\title{
Decadal Trends in Sea Level Patterns: 1993-2004
}

\author{
CARL Wunsch \\ Department of Earth, Atmospheric, and Planetary Sciences, Massachusetts Institute of Technology, Cambridge, Massachusetts \\ Rui M. PONTE \\ Atmospheric and Environmental Research, Lexington, Massachusetts \\ Patrick Heimbach \\ Department of Earth, Atmospheric, and Planetary Sciences, Massachusetts Institute of Technology, Cambridge, Massachusetts
}

(Manuscript received 5 January 2007, in final form 8 May 2007)

\begin{abstract}
Estimates of regional patterns of global sea level change are obtained from a $1^{\circ}$ horizontal resolution general circulation model constrained by least squares to about 100 million ocean observations and many more meteorological estimates during the period 1993-2004. The data include not only altimetric variability, but most of the modern hydrography, Argo float profiles, sea surface temperature, and other observations. Spatial-mean trends in altimetric data are explicitly suppressed to isolate global average long-term changes required by the in situ data alone. On large scales, some regions display strong signals although few individual points have statistically significant trends. In the regional patterns, thermal, salinity, and mass redistribution contributions are all important, showing that regional sea level change is tied directly to the general circulation. Contributions below about $900 \mathrm{~m}$ are significant, but not dominant, and are expected to grow with time as the abyssal ocean shifts. Estimates made here produce a global mean of about $1.6 \mathrm{~mm}$ $\mathrm{yr}^{-1}$, or about $60 \%$ of the pure altimetric estimate, of which about $70 \%$ is from the addition of freshwater. Interannual global variations may be dominated by the freshwater changes rather than by heating changes. The widely quoted altimetric global average values may well be correct, but the accuracies being inferred in the literature are not testable by existing in situ observations. Useful estimation of the global averages is extremely difficult given the realities of space-time sampling and model approximations. Systematic errors are likely to dominate most estimates of global average change: published values and error bars should be used very cautiously.
\end{abstract}

\section{Introduction}

Modern sea level rise is a matter of urgent concern from a variety of points of view, but especially because of the possibility of its acceleration and consequent threats to many low-lying parts of the inhabited world (see, e.g., Douglas et al. 2001; Church et al. 2001; Woodworth et al. 2004). The advent of high-accuracy satellite altimetry has led to estimates that, since about 1993, global average sea level has been rising at a rate of $2.8 \pm 0.4 \mathrm{~mm} \mathrm{yr}^{-1}$ (Leuliette et al. 2004; Cazenave and Nerem 2004, hereafter CN2004). Altimetry permits the avoidance of many of the problems associated with

Corresponding author address: Carl Wunsch, Room 54-1524, Massachusetts Institute of Technology, Cambridge, MA 02139.

E-mail: cwunsch@mit.edu the previous use of tide gauges (maldistribution, tectonic uplift, regional postglacial rebound effects), but estimates for earlier times remain dependent upon the prealtimetric data.

The altimetric measurements of sea level trends are now commonly taken as being the standard of reference. Figure 1, modified from CN2004 and S. Nerem (2005, personal communication), displays the decadal trends in sea level; large regional variations are visible-the spatial mean having been removed. Large regions of negative anomaly exceed the estimated mean rate of rise in these data, and thus imply a net local sea level drop, although obviously one cannot infer that one is observing a true secular trend anywhere.

Given the widespread and generally consistent reports of global warming, melting glaciers, shoreline retreat, and the clear trend of the last $20000 \mathrm{yr}$, a com-

DOI: 10.1175/2007JCLI1840.1

(C) 2007 American Meteorological Society 


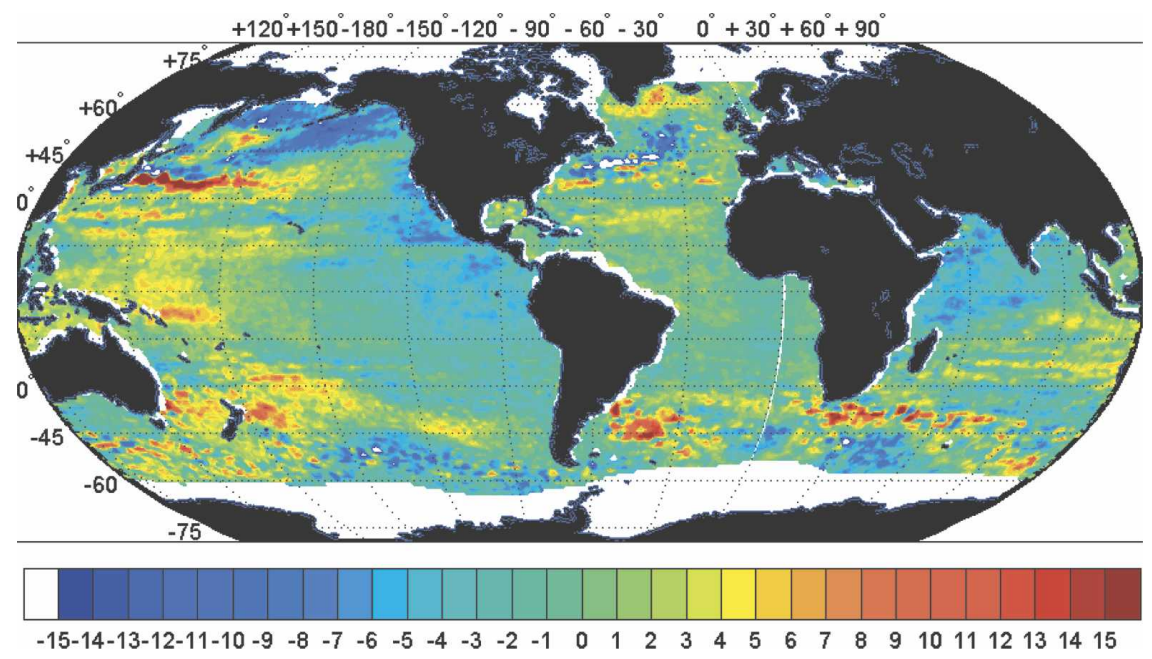

FIG. 1. Twelve-year (1993-2004) trend in sea level ( $\mathrm{mm} \mathrm{yr}^{-1}$; updated from CN2004) as determined directly from the TOPEX/Poseidon altimetric data. An area-weighted spatial mean of $2.8 \mathrm{~mm} \mathrm{yr}^{-1}$ was removed prior to plotting for direct comparison with the model results. Missing data areas show as white, as do a few obvious areas offscale in the negative direction.

pelling inference is that global-mean sea level is rising. Because the altimetric values are so widely quoted, it is desirable to buttress the values through independent means. Furthermore, obtaining a clear partitioning between warming and the addition of freshwater to the ocean has remained elusive, and the spatial patterns of rise and fall are very complex.

Determining global and regional sea level shifts would appear to be a reasonably straightforward process of forming averages of temperature and salinity measurements and then computing trends. In practice, almost no aspect of this problem is simple, and calculations with known accuracy are very difficult.

\section{a. Some preliminary numerics}

It is useful to begin by setting out some order of magnitude values involved in studying sea level changes whether from primarily data-based or model-based results, or from a combination of the two. Suppose, as seems reasonable, that annual global-mean sea level change (positive or negative) is of order $1 \mathrm{~mm} \mathrm{yr}^{-1}$. The mean ocean depth is $h_{0} \approx 3800 \mathrm{~m}$. Thus the volume or mass adjustment is $O\left(10^{-3} / 3800\right) \approx 3 \times 10^{-7} \mathrm{yr}^{-1}$. A useful rule of thumb is that in making estimates of signals, one should aim for a precision of better than $10 \%$ of the expected signal. If GCMs or data are to be used to study global sea level change, one must therefore aim for precisions in oceanic volume change of order $10^{-8} \mathrm{yr}^{-1}$. Whether such accuracies are now attainable remains to be seen.
Alternatively, suppose one seeks to use in situ measurements of temperature and salinity to estimate ocean warming/freshening changes (negative warmings and freshenings are included). A linearized equation of state, which is a useful approximation (see, e.g., Gille 2004) is

$$
\rho=\bar{\rho}(1-\alpha T+\beta S),
$$

where $\alpha \approx 1.7 \times 10^{-4} \mathrm{~K}^{-1}, \beta \approx 7.6 \times 10^{-4}, \bar{\rho} \approx 1029$, and $T$ and $S$ are temperature and salinity. For an order of magnitude, suppose the ocean were fully mixed in temperature and salinity. Then (e.g., Patullo et al. 1955) a pure temperature change gives rise to a "thermosteric" height change of

$$
h_{T}=\alpha \Delta T h_{0} .
$$

A $1 \mathrm{~mm} \mathrm{yr}^{-1}$ thermosteric change thus requires detecting an annual volume mean temperature change of about $1.5 \times 10^{-3}{ }^{\circ} \mathrm{C} \mathrm{yr}^{-1}$.

Suppose, instead, that there is no temperature change, but that $h_{m}=1 \mathrm{~mm} \mathrm{yr}^{-1}$ of freshwater is added or removed by glacial or groundwater storage changes (note that $h_{m}$ is not the "halosteric" change, which is defined differently; see below). Then the salinity change is

$$
\Delta S=-S_{0} \frac{h_{m}}{h_{0}},
$$

where $S_{0} \approx 35$ is the initial average salinity on the practical salinity scale. Thus $\Delta S \approx 10^{-5} \mathrm{yr}^{-1}$. 
Can one measure annual mean changes in temperature and salinity with these magnitudes, again with the hope of having a precision 10 times better?

One further set of values is useful for context. Greenhouse gas heating is supposed (e.g., Hansen et al. 2005; Pierce et al. 2006) to be of order $1 \mathrm{~W} \mathrm{~m}^{-2}$. If this amount of heat enters or leaves the ocean, the sea level change is about $1.3 \mathrm{~mm} \mathrm{yr}^{-1}$. To infer from external forcing that sea level has changed by $1 \mathrm{~mm} \mathrm{yr}^{-1}$ requires an estimated heating change of $0.8 \mathrm{~W} \mathrm{~m}^{-2}$, again with a goal of a precision 10 times better. If a value at one time is known with a standard error of $\sigma$, then the temporal difference of values - assumed independentwould have a standard error of $\sqrt{2} \sigma$ and tests of statistical significance require use of these numbers.

There are some important added complications in working at these accuracies, some of which are taken up below. Consider here only that the equation of state is significantly nonlinear (e.g., Jackett and McDougall 1995) and at the millimeter level the linearized equation of state is not sufficiently accurate. The cross terms of temperature and salinity plus the nonlinear temperature terms have to be included, and the equation of state is needed to infer the thermal and haline changes. The latter (Munk 2003) is particularly troublesome because an additional factor (the "Munk multiplier") of about 37 is required to convert the so-called halosteric change into the desired mass change $h_{m}$.

It is not clear at this stage whether the accuracies suggested here are easy or difficult to achieve. If they are challenging, an obvious strategy is to look for changes over, for example, a decade, in which the $1 \mathrm{~mm}$ $\mathrm{yr}^{-1}$ translates into a much more easily measurable, but still very difficult, $10 \mathrm{~mm}$ decade $^{-1}$ with equivalent larger changes in temperature and salinity. This strategy is reasonable and even practical, but it raises questions, taken up later, as to whether systematic errors in measurements or models do not also grow at similar rates over a decade. Do signal-to-noise ratios increase with time? Although the estimates described here represent only the 12-yr period 1993-2004, most of the difficulties encountered and described apply also to calculations made for arbitrarily long intervals with even fewer data. Thus the inferences in the literature for other, usually longer, periods are briefly discussed here as well.

\section{b. An approach}

Determination of accurate spatial averages does prove difficult, and this paper is thus divided into two parts. In the first, using nearly all of the extant temperature and salinity, altimetric, and other data available globally from 1992 to 2004, we discuss the regional variability in sea level and its contributing factors using a dynamically consistent general circulation model. It is found, as in Fig. 1, that regional variations are much larger than the expected global-mean values, thus much easier to determine, and so the system is inherently noisy. This noise is important in understanding the accuracy with which global-mean trends can be determined, and thus in the second part of the paper, we turn to a brief, not very conclusive, discussion of the calculations of the global averages.

The framework for our discussion is the Estimating the Circulation and Climate of the Ocean-Global Ocean Data Assimilation Experiment (ECCO-GODAE) state estimation machinery discussed by Wunsch and Heimbach (2007) and Köhl et al. (2007). In essence, the oceanic general circulation model at $1^{\circ}$ horizontal resolution with 23 vertical layers has been fit in a weighted, nonlinear, least squares sense to the global ocean observations. The model is an evolved version of that described by Marshall et al. (1997; the MITgcm), and a number of solutions to the least squares fit requirement now exist, varying in the details of how the model was configured, the duration, the particular data, and by the way in which the data were weighted in an overall misfit (objective or cost) function. A related effort is that of Carton et al. (2005) who used a much more limited dataset and a simpler optimization method that need not produce a dynamically consistent time evolution. Wenzel and Schröter (2007) describe a calculation in spirit somewhat like this one, although using a much smaller dataset than ours. ${ }^{1}$

These approaches differ fundamentally from a number of pure "forward" modeling simulations of oceanic heat uptake (e.g., Hansen et al. 2005; Pierce et al. 2006) in that the comparison of the model with the datasets is here fully quantitative, any misfit being explicitly determined point by point, data type by data type. Pierce et al. (2006) note that among various models, simulated regional heat exchanges with the atmosphere can differ by up to factors of 8 , and it is essential to determine whether any of these models is inconsistent with available observations.

An important conceptual point, and the source of some confusion, is that the results displayed here are from the unconstrained calculation by a forward model.

\footnotetext{
${ }^{1}$ Köhl et al. (2007) discuss sea level changes in a previous ECCO solution (v1.69) where the model configuration was somewhat different, the data duration was shorter, and the misfit function weights were also distinct. The process of model improvement and increased understanding of data errors is an asymptotic process, so that a definitive estimate will probably never be available, only improving ones.
} 
TABLE 1. Listing of the approximate numbers of most observational data types used to constrain the model. These values are only approximate because some derived quantities such as the NCEP-NCAR reanalysis and the hydrographic climatologies are far removed from direct observations. In the least squares calculation, each of these constraints requires an explicit weight, although in this version, bottom topography is not in the control vector and is effectively given infinite weight (as though perfect). Further data, e.g., tide gauges, have been withheld and are used as tests of system skill.

\begin{tabular}{lc}
\hline \multicolumn{1}{c}{ Meteorological variables } & No. \\
\hline NCEP-NCAR (6-hourly wind stress, buoyancy flux, shortwave/longwave radiation) & $2.1 \times 10^{9}$ \\
\hline Oceanographic variables & $3.3 \times 10^{7}$ \\
Altimetry (TOPEX, Jason-1, GFO, ERS-1/2, Envisat) & $1.9 \times 10^{7}$ \\
XBT & $2.1 \times 10^{7}$ \\
Argo profile temperature and salinity & $2 \times 10^{6}$ \\
CTD temperature and salinity & $1.6 \times 10^{7}$ \\
Hydrographic climatologies & $5.3 \times 10^{6}$ \\
Sea surface temperature & $1.5 \times 10^{6}$ \\
Tropical Rainfall Measuring Mission (TRMM) Microwave Imager (TMI) temperatures & 57600 \\
Gravity Recovery and Climate Experiment (GRACE) geoid & 57600 \\
Bottom topography & $1.0 \times 10^{7}$ \\
Quick Scatterometer (QuikSCAT) winds & $1.1 \times 10^{8}$ \\
Approximate No. of oceanographic observations & $2.11 \times 10^{9}$ \\
Approximate No. of total weighted values & \\
\hline
\end{tabular}

Before the model is run to produce the present results, it is first least squares fit to the data, as described, by adjusting its parameters (surface forcing, initial conditions, and in some experimental runs, interior mixing coefficients, etc.). Using those adjusted parameters, the model is then run forward in time, as in any ordinary model simulation, free of any constraints. This approach contrasts with some other methods (e.g., in most weather prediction systems using "assimilation") where the model is adjusted "on the fly" in the forward calculation, forcing it by various means toward the observations, and thus introducing unphysical temporal shifts. Because the datasets are comparatively thin during 1992, and there are indications of remaining starting transients during that year, results here are stated for the period 1993-2004.

To the extent that a least squares solution has been obtained, it depends directly upon the weights assigned to the different data types. To put it another way, the nature and structure of the solution depends upon the errors estimated for the data and for the model, which together determine the extent to which the solution is permitted to misfit. With too large a misfit, one is throwing away useful, probably essential, information; too small a misfit implies one is fitting noise. The importance of using accurate error estimates is exemplified by the recent withdrawal of the Lyman et al. (2006) inference of an upper ocean cooling, 2003-05, upon the discovery of a systematic error in much of their data (Willis et al. 2007), and the discussion by Gouretski and Koltermann (2007) of systematic biases in XBT datasets.

\section{The regional estimate}

The ECCO-GODAE solutions used here (see Wunsch and Heimbach 2007) employ approximately 100 million oceanographic data constraints and about two billion meteorological forcing variables (see Table 1). As in all least squares problems, every one of them requires a weight, but only a brief summary of the weighting is possible here. For present purposes, estimates of the errors in the main data types include those for altimetry (see Fu and Cazenave 2001), summarized by Ponte et al. (2007), in the hydrography and Argo data by Forget and Wunsch (2007), in the geoid and time-mean altimetry by Stammer et al. (2007), and the meteorological variables appearing in the control vector and taken initially from the National Centers for Environmental Prediction-National Center for Atmospheric Research (NCEP-NCAR) reanalysis of Kalnay et al. (1996). In this paper, the global-mean trends have been removed from all altimetric datasets, and as described later, the meteorological fields of freshwater and enthalpy flux have been subject to global balance constraints.

Although the calculations are ongoing and solutions slowly changing, the least squares estimate is now stable and provides generally acceptable misfits (as measured by estimated model and data errors) over the great bulk of the ocean and the entire period. Exceptions do exist, and we make no claim to be "correct," merely that we are going to use a "best-existingestimate," solution version v2.216 (the 216 is the iteration number; leading 2 refers to the model and data version). A variety of experiments with boundary con- 
TABLE 2. Six surface boundary condition combinations in wide use in oceanic GCMs. These differ in the way the continuity and salinity conservation equations are used. Here $h=h_{0}+\eta$, where $h_{0}$ is the unperturbed total depth. Definitions are RIGLID—rigid lid; VSF-virtual salt flux; LIN FS—linearized free surface; VFW—virtual freshwater flux; NLFS—nonlinear free surface; RFW-real freshwater flux. See P. Heimbach and J.-M. Campin (2006, unpublished manuscript). Unfortunately, determination of the slight mass addition to the ocean depends directly upon the accuracy of these representations. Condition 6 is the desired form, and the only one not placing an inappropriate source into the salinity conservation equation. Here, the freshwater results from conditions 2 and 6 are quite close, but 2, which we use, is capable of generating spurious circulations (see Huang 1993).

\begin{tabular}{ccccc}
\hline \hline No. & Continuity equation & Tracer conservation equation & \multicolumn{1}{c}{ Freshwater input } & Label \\
\hline 1 & $\boldsymbol{\nabla} \cdot h_{0} \mathbf{v}=0$ & $\partial_{t}\left(h_{0} S\right)+\boldsymbol{\nabla} \cdot \mathrm{h}_{0} S \mathbf{v}=-\mathrm{P} \cdot S_{0}$ & Virtual salt flux & RIGLID + VSF \\
2 & $\partial_{t} \eta+\boldsymbol{\nabla} \cdot h_{0} \mathbf{v}=0$ & $\partial_{t}\left(h_{0} S\right)+\boldsymbol{\nabla} \cdot h_{0} S \mathbf{v}=-\mathrm{P} \cdot S_{0}$ & Virtual salt flux & LINFS + VSF \\
3 & $\partial_{t} \eta+\boldsymbol{\nabla} \cdot h_{0} \mathbf{v}=\mathrm{P}$ & $\partial_{t}\left(h_{0} S\right)+\boldsymbol{\nabla} \cdot h_{0} S \mathbf{v}=-\mathrm{P} \cdot S$ & Virtual freshwater flux & LINFS + VFW \\
4 & $\partial_{t} \eta+\boldsymbol{\nabla} \cdot h_{0} \mathbf{v}=\mathrm{P}$ & $\partial_{t}\left(h_{0} S\right)+\boldsymbol{\nabla} \cdot h_{0} S \mathbf{v}=-\mathrm{P} \cdot S_{0}$ & Approx virtual freshwater flux & LINFS + A-VFW \\
5 & $\partial_{t} \eta+\boldsymbol{\nabla} \cdot h \mathbf{v}=0$ & $\partial_{t}(h S)+\boldsymbol{\nabla} \cdot h S \mathbf{v}=-\mathrm{P} \cdot S_{0}$ & Virtual salt flux & NLFS + VSF \\
6 & $\partial_{t} \eta+\boldsymbol{\nabla} \cdot h \mathbf{v}=\mathrm{P}$ & $\partial_{t}(h S)+\boldsymbol{\nabla} \cdot h S \mathbf{v}=0$ & Real freshwater flux & NLFS + RFW \\
\hline
\end{tabular}

ditions, data weights, and hundreds of iterations produces generally similar results for sea level change. Nonetheless, as with any large nonlinear optimization calculation, one cannot categorically rule out the appearance of qualitative changes as iterations proceedunlikely as that now appears. Efforts to improve the estimate will necessarily continue indefinitely.

The present model uses the Boussinesq approximation with a virtual salt flux boundary condition at the sea surface. Although it is an issue primarily for the discussion of global-mean sea level rise, we note here (see Table 2) that at least six surface boundary conditions are in use with ocean GCMs. Later reference will be made to this table.

In a Boussinesq approximation model (e.g., Greatbatch 1994), volume is conserved; the global average anomaly of elevation, $\eta(t)$, must vanish; and bottom pressure can fictitiously vary from net heating or cooling, for which a correction must be made. Regional results here use only the Boussinesq approximation elevations and bottom pressures without global average correction. The later global-mean discussion requires a different treatment.

\section{a. Regional results}

Figure 2 shows the local trends in relative sea surface height, $\eta$, with its standard error in Fig. 3, as determined prognostically from ECCO-GODAE v2.216. Figure 4 displays the trends in the model prior to optimization [i.e., without effects of data constraints and as described by Wunsch and Heimbach (2007)]. Comparison between the two fields reveals substantial differ-

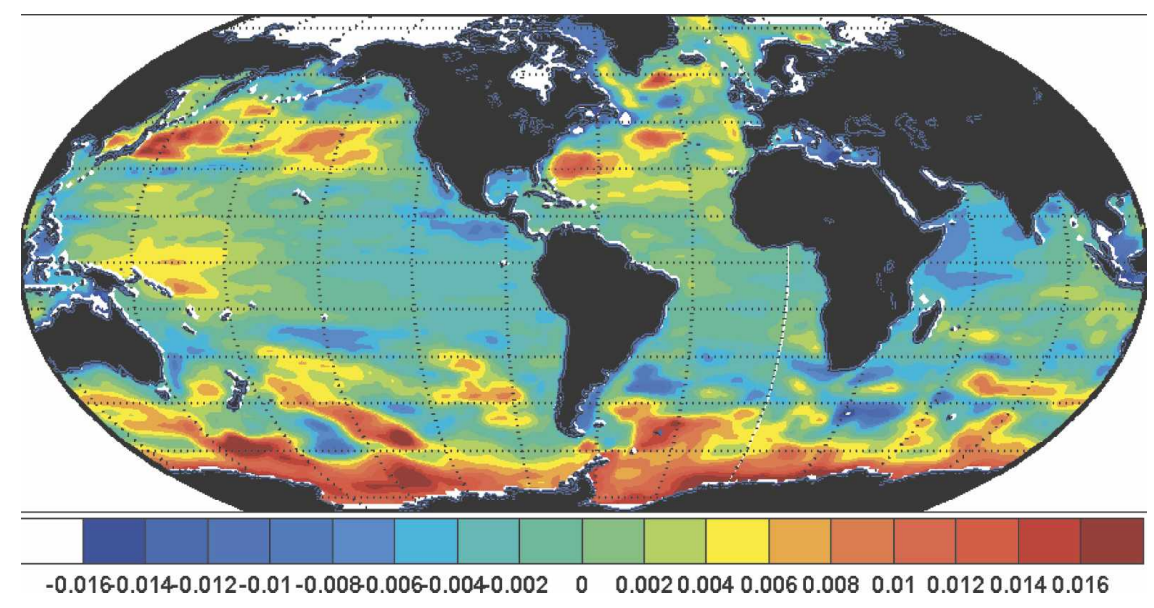

FIG. 2. Sea level trend $\left(\mathrm{m} \mathrm{yr}^{-1}\right)$ from solution v2.216 of the model computed over 1993-2004 and directly comparable to Fig. 1 apart from the greater area used. It is important that this figure be used with the partial error estimate shown in Fig. 3, particularly concerning the region around Antarctica where few data of any kind are available. (Here $\eta$ is defined as the prognostic value appearing in boundary condition 2 of Table 2, and in the Boussinesq approximation has zero spatial average.) 


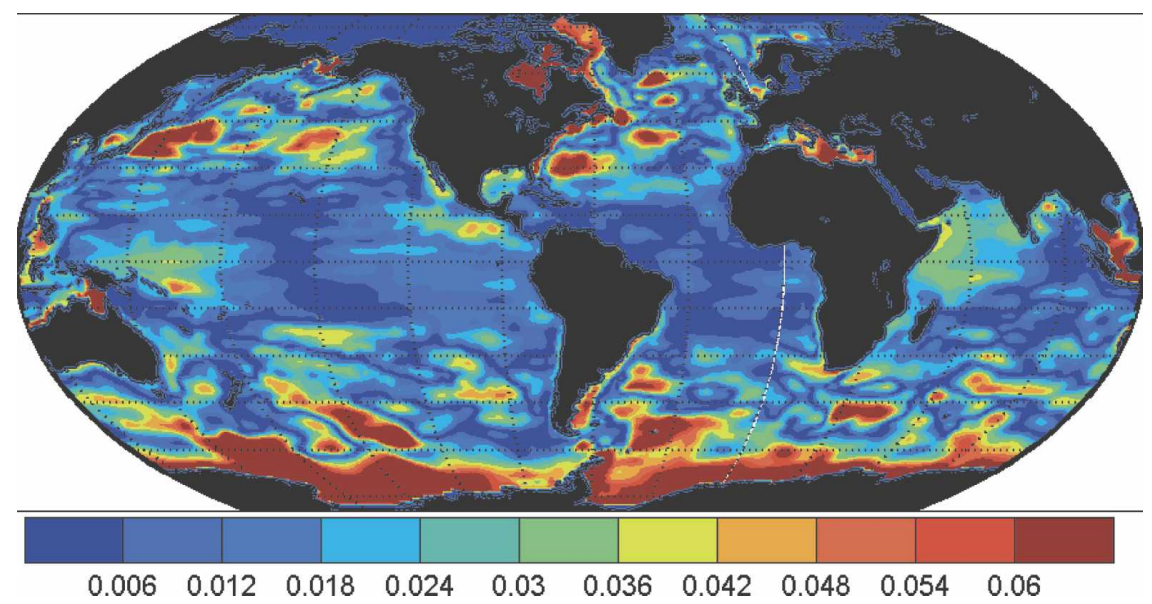

FIG. 3. Standard error $\left(\mathrm{m} \mathrm{yr}^{-1}\right)$ of the sea level elevation trend shown in Fig. 2. The values are determined from the straight-line fit to the time-varying monthly values, thus including the seasonal cycle, over $12 \mathrm{yr}$. Values shown here must be regarded as a lower bound on the true error as erroneous model elements (systematic errors) are not included nor is account taken of correlations in the residual of the straight-line fit.

ences in both sign and amplitude brought about by the optimization (e.g., notice the change from negative to positive trends over large parts of the Atlantic and the western tropical Pacific or the weaker positive trends over the Southern Ocean). Regional patterns are also clearly modified by the optimization (e.g., western North Pacific). Modifications to the forward run by data constraints are one measure of forward model errors owing to all possible sources.

In comparing the direct altimetric trend estimate (CN2004) as seen in Fig. 1, with that determined from the ECCO-GODAE model, one can see gross similarities, but some significant differences as well. For example, in the North Atlantic the CN2004 result shows less pronounced areas of increase. To interpret this difference, one must understand that the ECCO-GODAE calculation employs a spatially varying error estimate for the altimetric data (and similar error estimates for all the other data being used) that is shown in Fig. 5 (Ponte et al. 2007). Many sources of error are present, but they are dominated by the eddy variability not resolved by the model. In regions of intense eddy variability, the forcing of the model to the altimetric data is made very weak. In those regions, the model employs other datasets (e.g., hydrography, but they too are downweighted if it is a region of high estimated baroclinic variability) and dynamics to make its estimates.

The error contribution in Fig. 3 is obtained from time

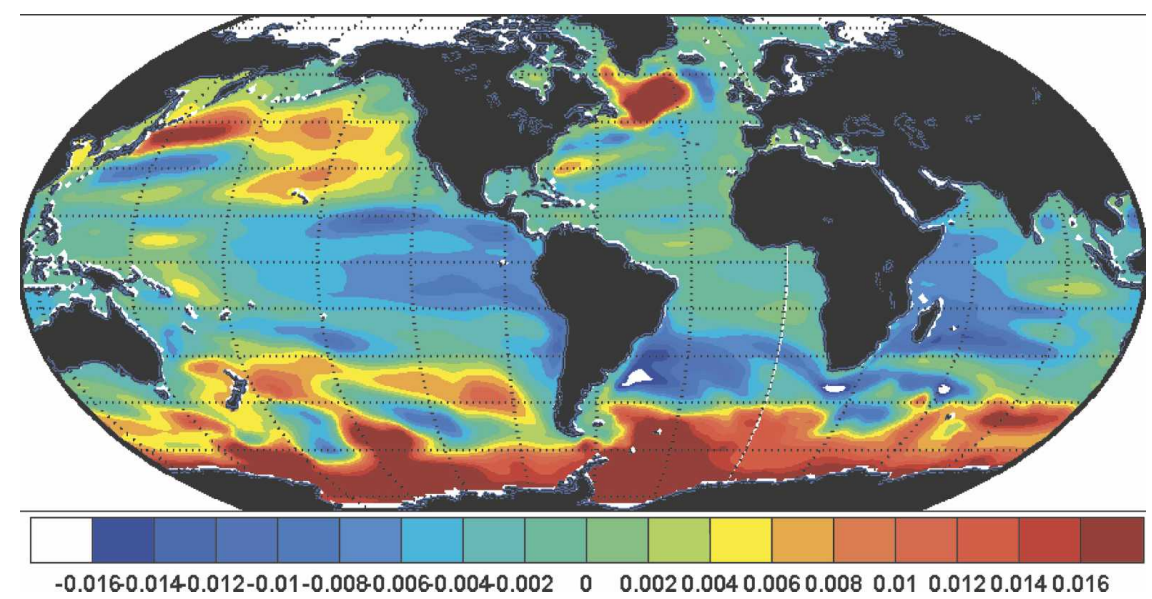

FIG. 4. Trends $\left(\mathrm{m} \mathrm{yr}^{-1}\right)$ of sea level over $12 \mathrm{yr}$ in the nonoptimized model. Differences from the result in Fig. 2 are due to the fitting of the model to all the observations by adjustment of initial conditions and meteorological forcing. 


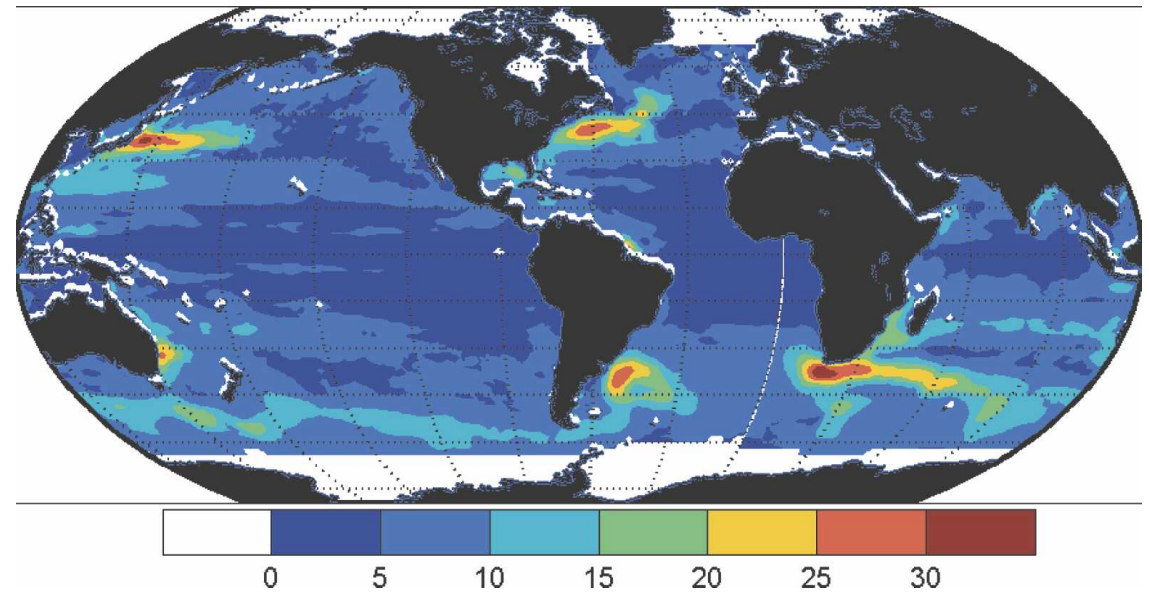

FIG. 5. Estimated RMS error of the time-dependent component of the altimetric data $(\mathrm{cm})$ as discussed by Ponte et al. (2007, their Fig. 3). Low-frequency variability is not included.

variability in the model estimates-that is, the estimated uncertainty from the least squares fit of a straight line to the data-and is a lower bound on the complete error. Evidently, the reliability of the results varies greatly with position and most of the pointwise values are not statistically significant. ${ }^{2}$ The appearance, however, of large-scale patterns of the same sign suggests both that they are robust features and that a prior statistical model based upon spatially uncorrelated signal and noise is incomplete. Provision of a full error estimate for Fig. 2, including model error, is underway but is not yet available. Note that the model domain, $\pm 80^{\circ}$ of latitude, significantly exceeds the domain of coverage by the altimeter alone [approximately $\pm 65^{\circ}$ for the major Ocean Topography Experiment (TOPEX) Jason-1 datasets] owing both to the particular orbit inclinations and difficulties with altimetry in the presence of floating ice, even where some altimetry does reach higher latitudes. In broad outline, the model follows the regional altimetric changes, but with important deviations.

The main issue is one of attribution. Absolute sea

\footnotetext{
${ }^{2}$ The inference that a linear trend is an adequate representation of the fields can only be determined by a point-by-point analysis of the residuals left by the straight-line fit. A subsample of the trends and monthly mean values examined visually suggests that a linear trend is a reasonable description of much of the lowfrequency variability. Comparison of maps of the difference between the mean of 2004 and the mean of 1993 shows a very strong resemblance to that of the trend. Maps (not shown) of the fraction of variance attributable to a linear trend do, however, show a very wide geographical dependence. The standard errors (Fig. 3) are based upon the assumption of white noise residuals, and in the present instance should be regarded as only a crude representation of part of the uncertainty.
}

level that is not arising from vertical shifts of land observers can change regionally for a number of reasons: 1) warming/cooling, $\mathcal{H} ; 2$ ) evaporation $E$, precipitation $P$, and runoff $R$ (exchange of freshwater with the atmosphere and land) in the combination $\mathcal{E}=E-P-$ $R ; 3)$ redistribution by advection and diffusion of mass within the ocean; 4) changes in ocean volume from tectonics and postglacial rebound (e.g., Peltier 2001); and 5 ) modification of local gravity by glacial ice removal and postglacial rebound (Mitrovica et al. 2001). Ice volume changes also lead to expected shifts in the geocenter and earth rotation with sea level consequences. We will not discuss reasons 4 or 5 here.

\section{b. The density changes}

To what does one attribute the patterns observed in Fig. 2? Changes in temperature and salinity within the water column will modify the density field. Ignoring the distinction between temperature and potential temperature, density and potential density, perturbations in $T, S$ lead to a perturbation,

$$
\Delta \rho=\bar{\rho}(-\alpha \Delta T+\beta \Delta S) .
$$

Although there is a certain symmetry in Eq. (4), the local effects of temperature and salinity are quite different in the real, compressible, ocean. If the water column is heated, the fluid expands and sea level rises, the bottom pressure through the hydrostatic approximation remaining unchanged because the total fluid mass has not changed. If one, instead, adds salt to the column of fluid, mass has been added, the salinity increases, and so does the bottom pressure (but physically, only freshwater is ever added or subtracted, not salt, and the misnomer "haline contraction," as an ana$\log$ to thermal expansion, should be avoided). 


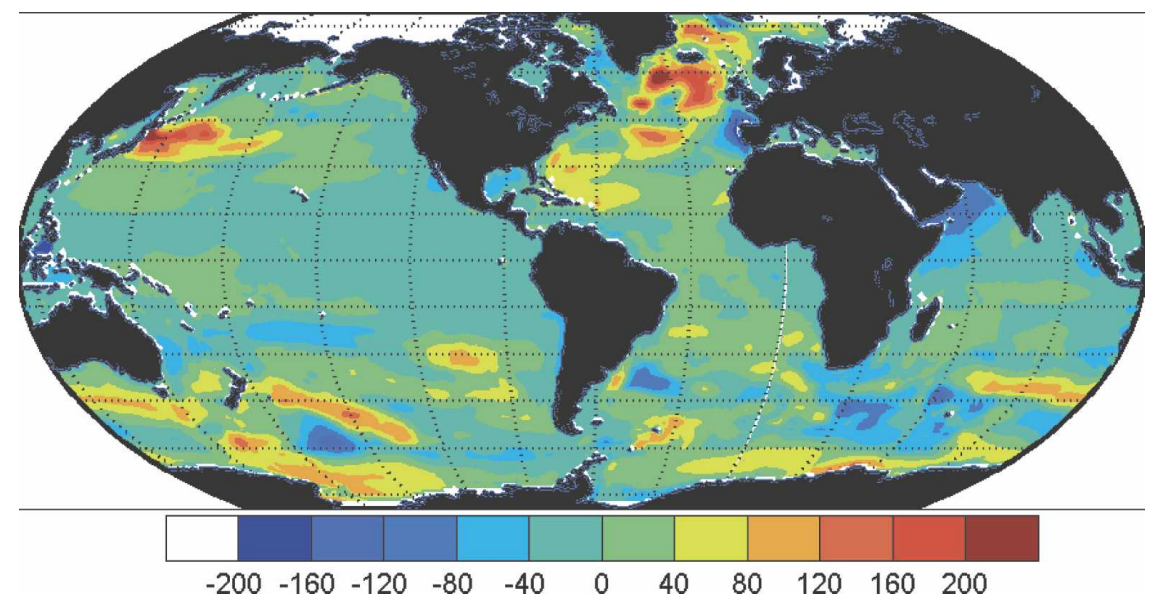

FIG. 6. Vertically integrated trend in temperature in v2.216 in ${ }^{\circ} \mathrm{C} \mathrm{m} \mathrm{yr}^{-1}$. Thus a value of 100 at the mean model depth of $3828 \mathrm{~m}$ corresponds to a column average temperature change of $0.026^{\circ} \mathrm{C} \mathrm{yr}^{-1}$. The spatial mean, which has been removed, is $2.1^{\circ} \mathrm{C} \mathrm{m} \mathrm{yr}{ }^{-1}$ or $5.5 \times$

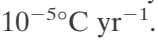

The "mass" height $h_{m}$ is the contribution from the addition or subtraction of freshwater. ${ }^{3}$ As Munk (2003) emphasized, it is not the same as the so-called halosteric height $h_{S}$, which is the apparent expansion or contraction of the water column from a change in the average salinity (Patullo et al. 1955),

$$
h_{S}=\frac{\beta \Delta S}{1+\beta S_{0}} h_{0} \approx \beta \Delta S h_{0} .
$$

The relationship between the salinity change and mass height is given by Eq. (3), which implies

$$
h_{m} \approx \frac{h_{S}}{\beta S_{0}},
$$

where the "Munk multiplier," $1 / \beta S_{0} \approx 36.7$, is a large number.

Figure 6 depicts the vertically integrated trends in the temperature field, and Fig. 7 is the corresponding chart for the salinity change. These produce density trends, $\Delta \rho_{T}, \Delta \rho_{S}$, respectively, from temperature and salinity alone. Overall, there is a strong tendency for the two trends to be compensating, except in high southern latitudes. The striking salinity increase in the northern North Atlantic is consistent with the inference of Curry and Mauritzen (2005) that the earlier freshening there had reversed beginning in the 1990s. Thus the com-

\footnotetext{
${ }^{3}$ We avoid the term "eustatic" change, whose technical meaning is the globally uniform shift in sea level (Oxford English Dictionary, or Douglas et al. 2001). Such a change can occur from either uniform heating/cooling or addition of freshwater, and so is ambiguous. As seen in Figs. 1 or 2, it is not even clear whether such a change is physically meaningful on a decadal time scale.
}

bined density change $\left(\Delta \rho_{T S}\right.$, accounting for nonlinearities in the equation of state) shown in Fig. 8 is weaker than from either contribution alone, with about $25 \%$ of the temperature variance being compensated by salinity changes. Figure 9 shows the 12-yr mean of net evaporation $\mathcal{E}$. The expected patterns of evaporation and precipitation are visible. A similar map exists for the thermal forcing $\mathcal{H}$. Trends exist in both $\mathcal{H}$ and $\mathcal{E}$ (not shown) and in the wind field, but the dominant regional model trends occur not because of forcing trends, but because the model is not in full equilibrium with the local average meteorological fields and is still responding to forcing events-possibly long prior to 1992-as reflected in the estimated initial conditions.

The tendency of temperature and salinity to display compensating contributions to the density change strongly suggests adiabatic horizontal and vertical displacements of water masses (general circulation changes) as a major contributor to the observed sea level fluctuations, because atmospheric changes in $\mathcal{H}$ and $\mathcal{E}$ are unlikely to lead to compensating temperature and salinity shifts. Figure 10 depicts trends in bottom pressure, a regionally varying combination of heating/ cooling and sea level change. The most notable feature is again the spatial complexity. No inference can be made as to the future continuation of any of the regional trends.

\section{c. Elevation change components}

The relationship among temperature and salinity changes to density, bottom pressure, and surface elevation trends is complicated. It can be summarized in the 


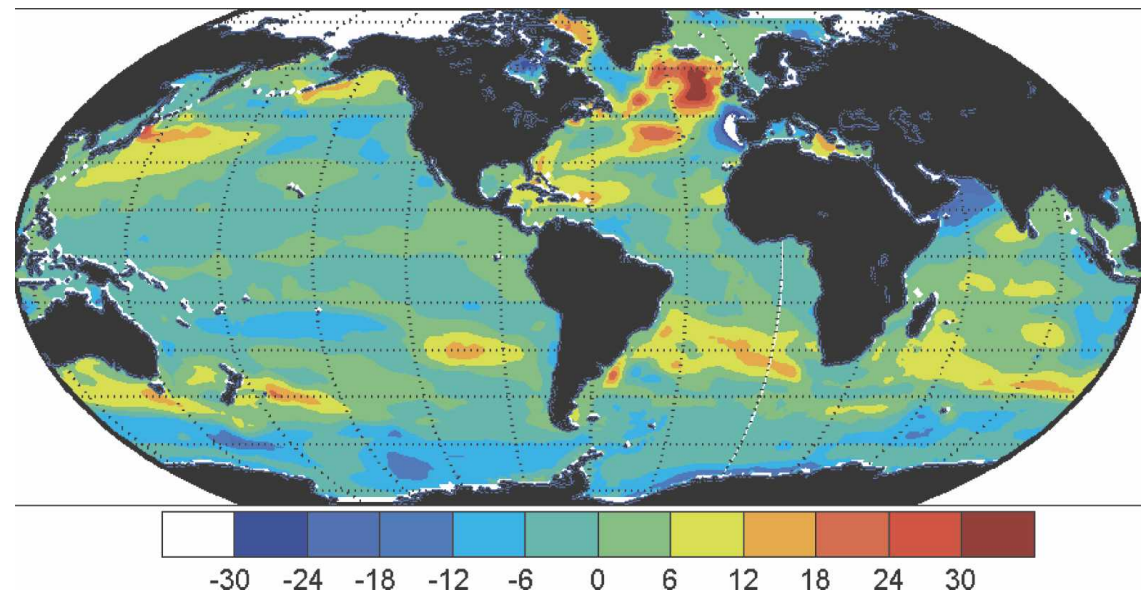

FIG. 7. Trends in the v2.216 vertically integrated salinities $\left(\mathrm{m} \mathrm{yr}^{-1}\right)$. Thus a value of 10 at the mean model depth corresponds to a salinity trend of $2.6 \times 10^{-3} \mathrm{yr}^{-1}$ on the practical salinity scale. The mean, corresponding to $-1.3 \times 10^{-4} \mathrm{yr}^{-1}$, has been removed before plotting. See Curry and Mauritzen (2005) for a discussion of the North Atlantic high-latitude changes.

spatial correlation matrix (Table 3). The strong anticorrelations between temperature and salinity trends, and between those in $\eta$ and $\rho$, are shown.

The term $\Delta \eta$ is strongly correlated in magnitude with the density integral and more weakly with the bottom pressure change, $\Delta p_{b}$, but $\Delta p_{b}$ and the integral of $\Delta \rho_{T S}$ are themselves correlated and so the correlations are not directly translatable into variance contributions. [The problem is a direct analog to that of expanding a vector in two nonorthogonal vectors, and no further simple physical statement can be made about the cause from this approach, although statisticians employ partial correlation coefficients to describe relative contri- butions; see Jenkins and Watts (1968).] No single element dominates the regional trends in $\eta$-it is a summation of thermal, salinity, and dynamical shifts coupled through the equations of motion.

\section{Vertical structure and abyssal contribution}

Because of the relative paucity of data, the contribution to the height change from regions below the upper ocean has generally been omitted (e.g., Antonov et al. 2005). Ishii et al. (2006) and Lombard et al. (2006) confine their analyses to the upper $700 \mathrm{~m}$, Willis et al. (2004) to $750 \mathrm{~m}$, while Carton et al. (2005) stop at 1000

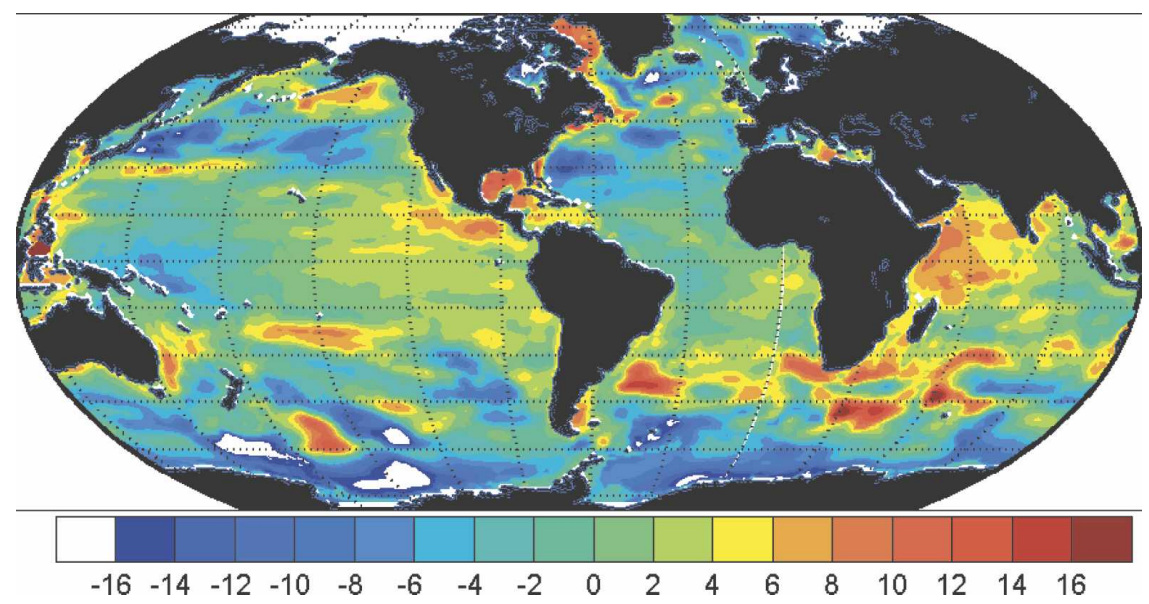

FIG. 8. Density trends $\left(\mathrm{kg} \mathrm{m}^{-2} \mathrm{yr}^{-1}\right.$; very close to $\left.\mathrm{mm} \mathrm{yr}^{-1}\right)$ owing to the combined effects of temperature and salinity $\left(\Delta \rho_{T S}\right)$. The result is not exactly equal to the sum of the temperature and salinity trends because the equation of state is nonlinear in $T$ and $S$, but the effect is very small (e.g., Gille 2004). 


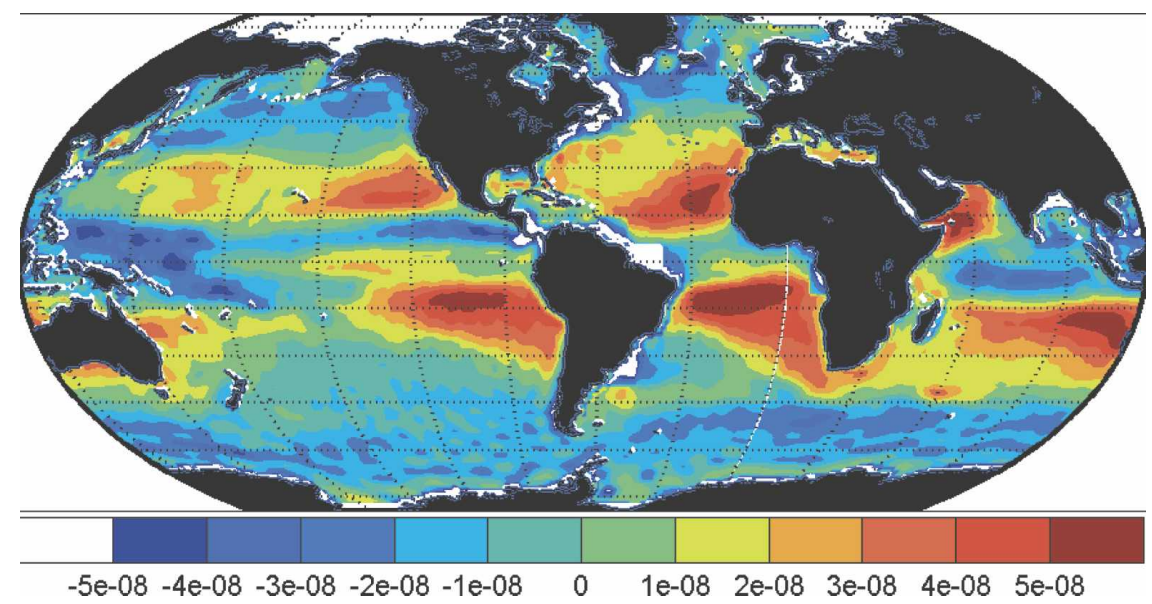

FIG. 9. Twelve-year mean (not the trend) net $E-P-R=\mathcal{E}\left(\mathrm{m} \mathrm{s}^{-1}\right)$ from the optimized solution v2.216. The small-scale jitter originates in the NCEP-NCAR reanalysis and is not a consequence of the optimization. Small trends (not shown) exist in these values, but oceanic trends are largely a result of imbalances with the mean fields.

$\mathrm{m}$; Antonov et al. (2005) uniquely go to $3000 \mathrm{~m}$ (see Table 4). On multidecadal time scales, one expects the full oceanic water column to contribute. From the model, and the data that are available, the contribution from density changes over the entire water column can be evaluated for the time span of the present analysis, with the reservation that direct observations below $2000 \mathrm{~m}$ remain sparse, and estimates in the Southern Ocean in particular rely proportionally heavily on residuals of global conservation integrals and on local model dynamics.

Figure 11 displays the trend in the zonal sum of the density change over $12 \mathrm{yr}$ from the model result, as well as the separate temperature and salinity contributions.
In general, the major contributions come from above $847.5 \mathrm{~m}$, but the fraction in that depth range can both exceed the vertical total and be significantly less as a function of latitude. In the Southern Ocean relative contributions are a complex function of depth and latitude.

The zonal sums between 0 and $847.5 \mathrm{~m}$ in Fig. 11 can be compared with similar quantities estimated by Willis et al. (2004; cf. their Fig. 9) above $750 \mathrm{~m}$ based on a pure data analysis involving both altimeter and in situ temperature observations. The patterns in temperature are broadly similar to theirs in mid- and low latitudes, and in a region of warming around $40^{\circ} \mathrm{S}$ and in high northern latitudes, but differ in detail, particularly near

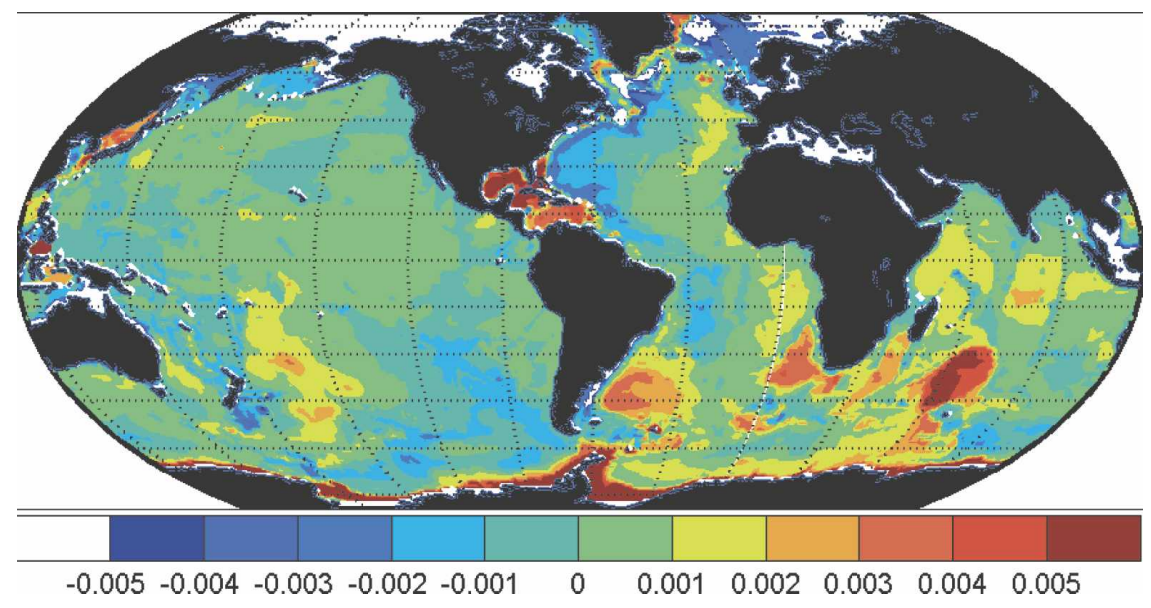

FIG. 10. Contours $\left(\mathrm{m} \mathrm{yr}^{-1}\right)$ of Boussinesq bottom pressure change in the ECCO v2.216 result. The global-mean decline is removed here. The Kerguelan Plateau, southeast of the Cape of Good Hope, is a region of a strong increase in bottom pressure, but contributes little to the global averages. 
TABLE 3. The symmetric correlation matrix of variables entering computation of surface elevation trends. Here $\rho_{T}$ and $\rho_{S}$ denote the density trends owing to temperature and salinity alone, the other variable being held fixed, and $\Delta$ denotes the trend; $\Delta \rho_{T S}$ denotes the combined, total density trend. Correlations are not area weighted. Area Wgtd. refers to std devs $\left(\mathrm{mm} \mathrm{yr}^{-1}\right)$ of trends computed by area weighting the $1^{\circ}$ squares.

\begin{tabular}{lrcccc}
\hline \hline & $\int \Delta \rho_{T}$ & $\int \Delta \rho_{S}$ & $\int \Delta \rho_{T S}$ & $\Delta \eta$ & $\Delta p_{b}$ \\
\hline $\int \Delta \rho_{T}$ & 1 & -0.54 & 0.65 & -0.53 & 0.08 \\
$\int \Delta \rho_{S}$ & -0.54 & 1 & 0.29 & -0.22 & 0.07 \\
$\int \Delta \rho_{T S}$ & 0.65 & 0.29 & 1 & -0.80 & 0.16 \\
$\Delta \eta$ & -0.53 & -0.22 & -0.80 & 1 & 0.47 \\
$\Delta p_{b}$ & 0.08 & 0.07 & 0.16 & 0.47 & 1 \\
Area Wgtd. trend & $6.3^{2}$ & $4.7^{2}$ & $5.1^{2}$ & $5.3^{2}$ & $3.2^{2}$ \\
$\quad$ variance & & & & & \\
\hline
\end{tabular}

$20^{\circ} \mathrm{N}$ and $\mathrm{S}$ and in the absence here of the strong cooling they see at about $38^{\circ}-50^{\circ} \mathrm{N}$.

Figures 12 and 13 show the patterns of temperature and salinity trends between 985 and $1750 \mathrm{~m}$, and Figs. 14 and 15 show the $985 \mathrm{~m}$ to the bottom trends over the model duration and display the complexity of the change even at depth. Omission of the ocean below the main thermocline does, for the 12 -yr period, give a useful estimate of ongoing behavior, although there are quantitative errors. Whether that will remain true as global change continues and anomalies have time to penetrate the abyss remains to be seen. Figure 16 suggests significant warming in the Southern Ocean and along the North Atlantic margin, roughly coinciding with the position of the deep western boundary current there.

\section{The spatial mean}

We turn now to the problem of determining the global trend means, which as described in the introduction, are small residuals of large spatial and temporal variations. Because of the difficulties with both datasets and models, much of the result here is inconclusive: the reliability of the global average estimates remains poorly known. Appendix A contains a more extended discussion of the many troublesome details.

A number of authors have grappled with the problem

TABLE 4. Representative estimate of global-mean sea level rise and its thermosteric and freshwater contributions for recent years. Error estimates are likely all overly optimistic as they do not include systematic errors. Each value involves important assumptions not described in the table.

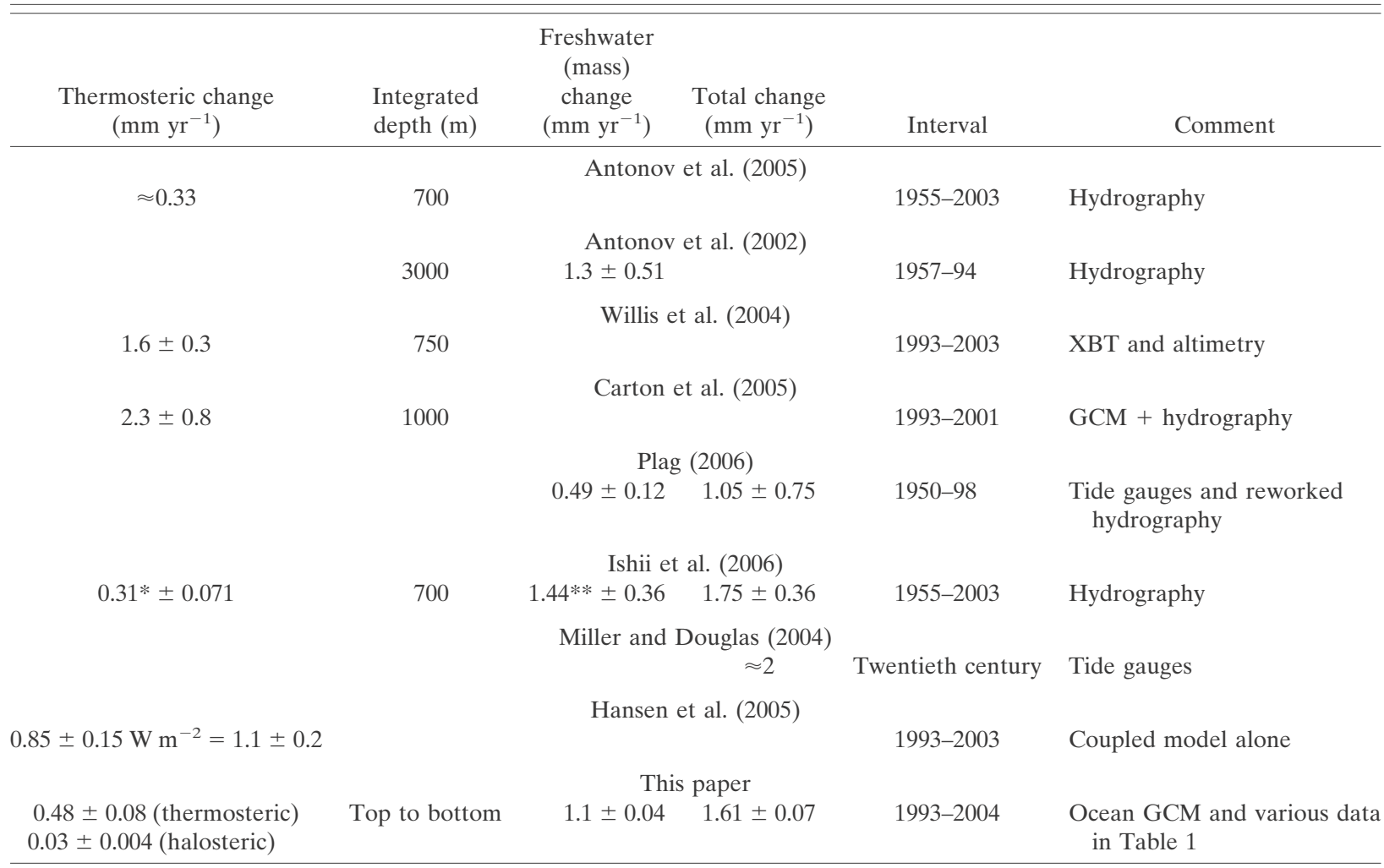

* $1.2 \pm 0.3$ for $1995-2003$.

** Converted from halosteric. 


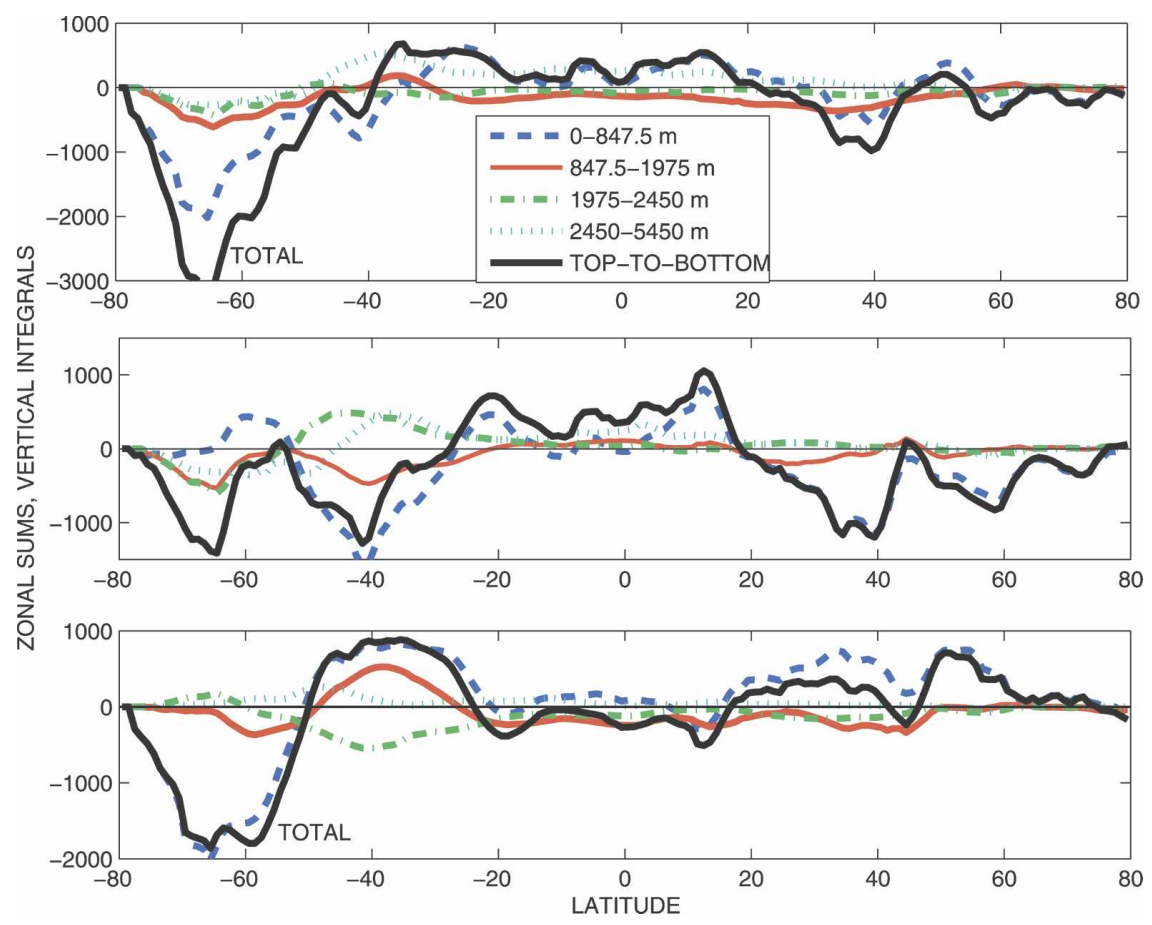

FIG. 11. Zonal sums of the trends in vertical integrals of the (top) model density anomaly $\left(\mathrm{kg} \mathrm{m}^{-2} \mathrm{yr}^{-1}\right)$, (middle) from temperature pattern alone, and (bottom) from salinity alone. Solid, black curve is the total top-to-bottom change. Dashed blue curve is the contribution from the main thermocline and above, red is from the thermocline to $1975 \mathrm{~m}$, green is from 1975 to $2450 \mathrm{~m}$, and cyan is from 2450 to the maximum model depth. Where the dashed blue curve is near the black, the ocean above about $850 \mathrm{~m}$ accounts for the entire change, although often that occurs because temperature and salinity contributions tend to cancel at depth. Middle latitudes and parts of the Southern Ocean display significant deviations from upper ocean dominance. For temperature note again that a negative density anomaly corresponds to warming.

of determining the spatial means from in situ and altimetric data (see Table 4). Here, existing estimates of the spatial means are referred to as "subglobal" to distinguish them from the goal of truly global ones. Even the problem of forming an average, specifically of trends, requires comment because almost all model averages are small residuals of fields with large fluctuations, and at least four different methods for computing the averages can be considered (see appendix A). The terminology of global averages must be used cautiously to avoid the implication that the ocean displays anything approaching a uniform linear trend (it plainly does not). The quotation of averages is simply an intuitively accessible surrogate for global fluid oceanvolume changes, however distributed, as measured in cubic meters per year.

Each of the datasets (commonly tide gauges, altimeters, hydrographic measurements) has troubling issues of space-time sampling and of physical interpretation. Altimetric data (CN2004) are widely accepted as providing the best available estimate of mean global sea level rise, although errors in the time-varying components of altimetric datasets are complex and not wholly quantified. As summarized in appendix B, the major sampling issues concern the cutoff at about $60^{\circ} \mathrm{S}$ from orbital configuration or floating sea ice, and the possibility of trends in the long list of corrections made to the data.

For hydrography, the major problems consist of the very irregular space-time sampling, the bias toward the upper ocean, the seasonal cycle in sampling in the presence of a strong seasonal signal, and the possibility of systematic errors as the technology for salinity, temperature, and depth determination changed over the last 50 yr. Tide gauge problems have been widely discussed (e.g., Douglas et al. 2001).

The models introduce a very large number of approximations and errors, some connected with the datasets and some connected to the numerics and physical approximations. As noted in the introduction, a sea level change of $1 \mathrm{~mm} \mathrm{yr}^{-1}$ in an ocean of mean depth near $4000 \mathrm{~m}$ implies a fractional volume or mass 


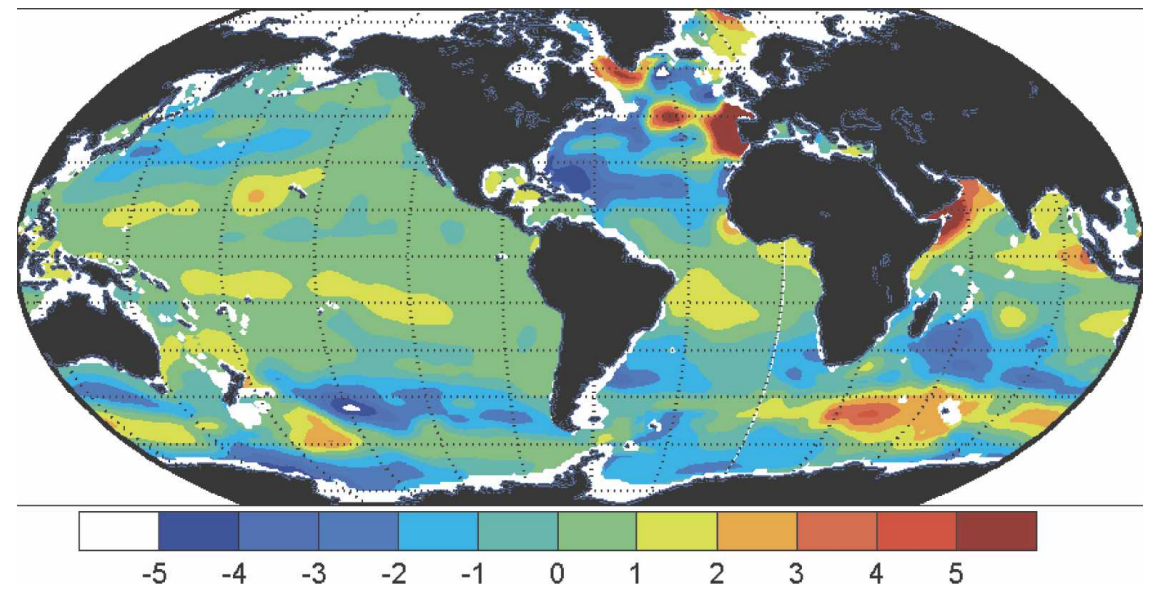

FIG. 12. Spatial pattern in layers 14 and 15 (between 985 and $1750 \mathrm{~m}$ ) of the density trend owing to temperature alone. Blue areas correspond to warming, i.e., a density decrease. Units

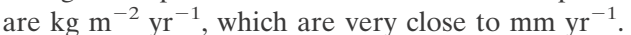

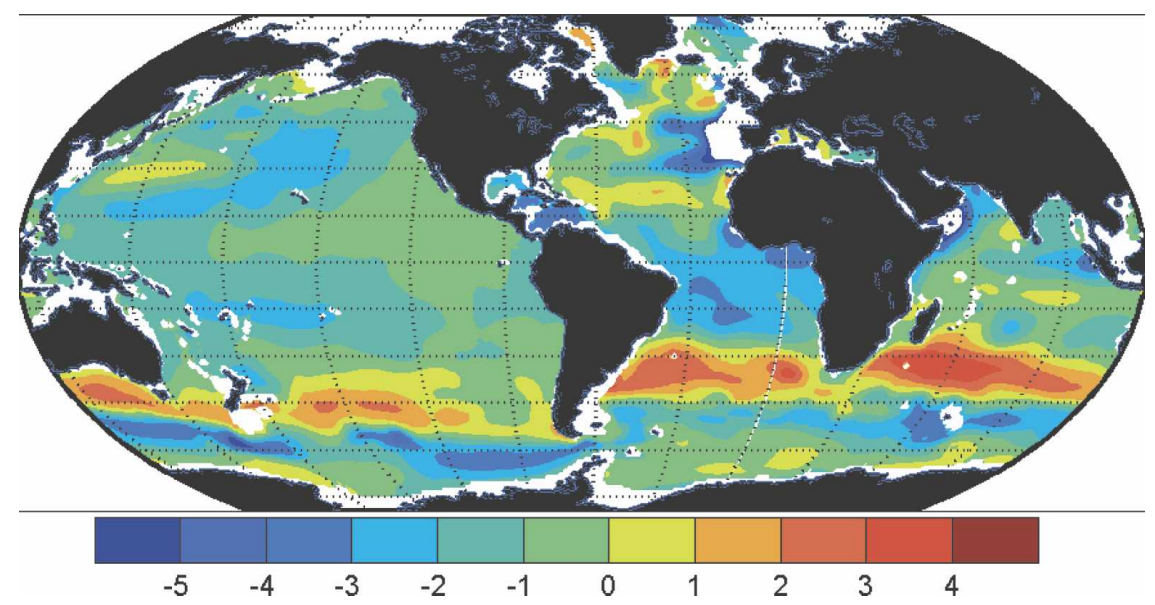

FIG. 13. Same as in Fig. 12, but for salinity. Here blue areas correspond to freshening (decreasing density).

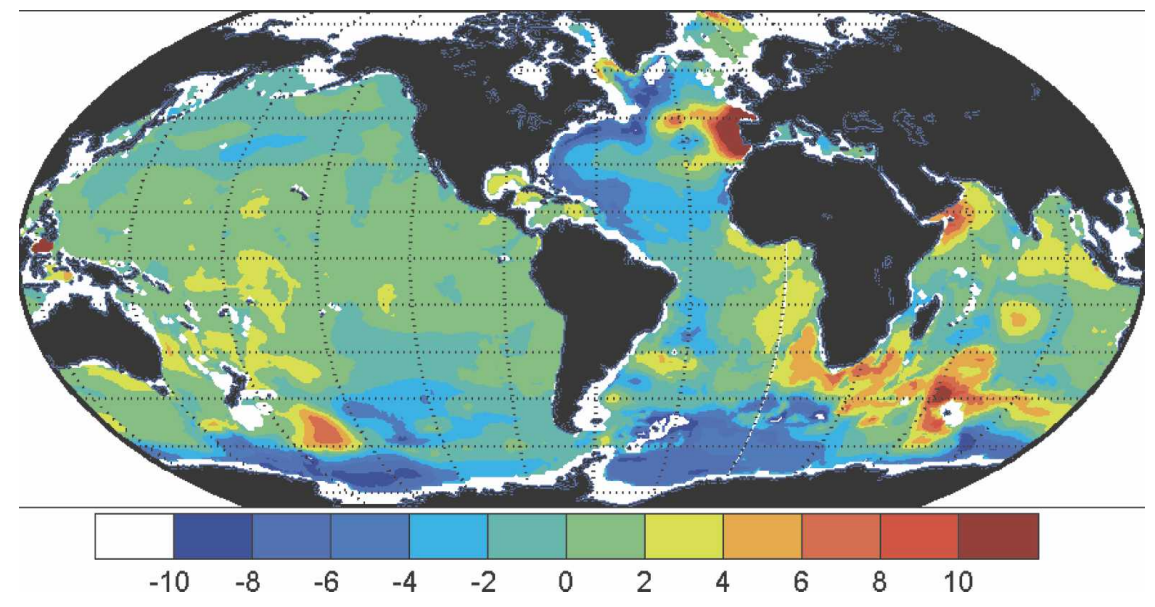

FIG. 14. Integral from $910 \mathrm{~m}$ to the bottom of the density anomaly trend owing to temperature alone. 


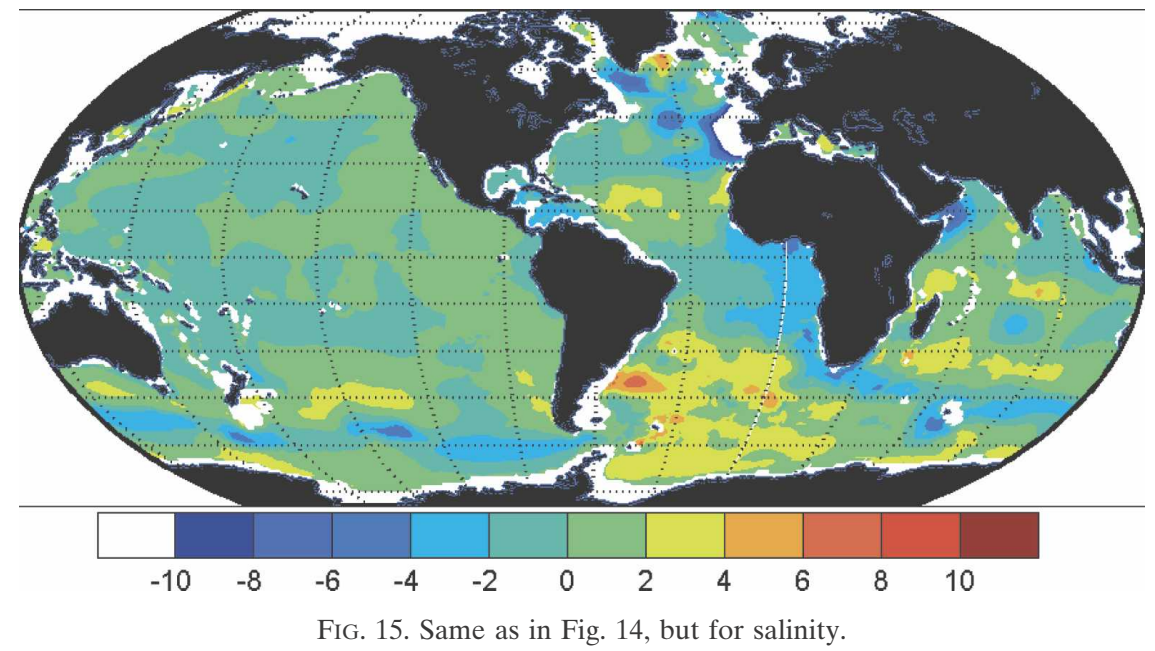

change of $3 \times 10^{-7}$ per year of integration time. Determining whether such accuracies are now achievable with a GCM leads one to examine a very long list of approximations made in any numerical model. Without claiming to have a definitive answer, appendix C out-
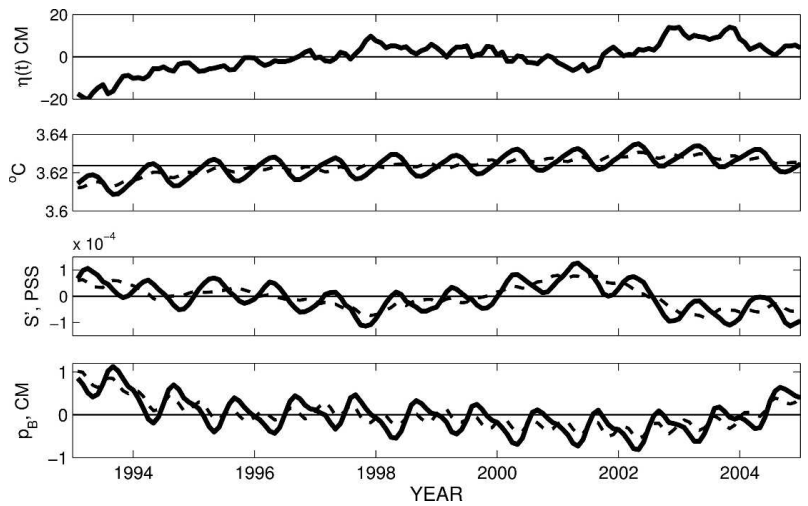

FIG. 16. Monthly mean values of diagnosed estimated globalmean surface height, $\bar{\eta}(t)$, model temperature, salinity anomaly, $S^{\prime}$, and bottom pressure, $p_{B}(t)$. The bottom pressure is the Boussinesq model value, not corrected for global thermal effects, while $\bar{\eta}(t)$ is so corrected because the prognostic Boussinesq $\eta(t)$ has zero global mean. Estimated sea level fall between 1998 and about 2001, and again in 2004, is more correlated with the salinity anomaly $\left(S^{\prime}\right)$ change than with the temperature, suggesting variations in land-ice volume. Dashed curves display results with a suppressed annual cycle so that a residual semiannual cycle becomes visible. Salinity anomaly is used rather than salinity to minimize the round-off errors. Note that the subset of the Argo float data, now known to have been miscalibrated (Willis et al. 2007), were present in the datasets used here and might account for some of the apparent relative decline in sea level between about 2003 and 2005, although many other data are used as well. Future estimates will, however, suppress these errors, and in the meantime no particular significance is attached to the result as it is a comparatively minor feature. lines some of the issues. Table 2 lists six different surface boundary conditions for salt and freshwater in common use. Attempts here at using several of them show that they can produce differences in apparent sea level trends approaching an order of magnitude. As appendix $\mathrm{C}$ discusses, we rely primarily upon the linear freshwater/virtual salt flux formulation, as it was both adjointable 4 and produced consistent results for salinity, density, and sea level changes.

In the current Boussinesq approximation model, a conversion from volume conservation to mass conservation is required; this conversion (e.g., Greatbatch 1994) is itself an approximation. Further references can be found in appendix C. Because a Boussinesq model produces an elevation change $\eta$ whose global mean is by definition zero, one must diagnose the global-mean change $\Delta \bar{\eta}$ as

$$
\Delta \bar{\eta}=-\Delta \bar{p}_{b}-\Delta \bar{\varepsilon}
$$

or

$$
\Delta \bar{\eta}=-1 / \bar{\rho} \int_{-h}^{0} \Delta \rho_{T S} d z-36.7 / \bar{\rho} \int_{-h}^{0} \Delta \rho_{S} d z,
$$

where $\Delta \rho_{T S}$ is the total density change, and $\Delta \rho_{S}$ is the change in density owing to salinity change alone. The value 36.7 is the Munk multiplier, $z=-h$ is the water depth, and $\bar{\rho}$ is a reference density $\left(1029 \mathrm{~kg} \mathrm{~m}^{-3}\right)$.

Most ocean GCMs, even if not optimized, are forced by surface boundary conditions including net heating $\mathcal{H}$, and net estimated evaporation minus precipitation minus runoff $\mathcal{E}$ from the atmospheric reanalyses and

\footnotetext{
${ }^{4}$ The model adjoint is used to carry out the least squares minimization. See Wunsch and Heimbach (2007).
} 
where runoff is taken from Fekete et al. (2002). Available reanalyses are derived from weather forecast models that do not impose global balances for freshwater and heat. In addition, the runoff component from melting glacial ice is subject to great controversy, including even its sign (e.g., Cazenave 2006). Imbalances in surface forcing can easily give rise to systematic errors of the magnitude of the signal we seek. Other issues, such as the absence of geothermal heating, become troublesome over the longer time scales.

\section{Estimation-system global means}

The ECCO-GODAE global-mean estimates are dependent approximately equally on the assumptions of the absence of spurious trends in model dynamics/ kinematics, and in the various datasets. We here will state the estimated global trends, with formal error bars, but we believe the greatest uncertainty in the results lies with the possibility of systematic errors in both data and model, and for which we lack quantitative estimates. Formal error bars, referring only to the expected stochastic errors, are commonly quoted as though they represent total uncertainties, and they are probably misleadingly optimistic.

In the ECCO-GODAE calculations, the spatialmean sea level trend was removed from the altimetric datasets. [The area-averaged trend in the European Remote Sensing Satellite-1 and -2 (ERS-1, -2)/Environmental Satellite (Envisat) data is $2.3 \mathrm{~mm} \mathrm{yr}^{-1}$; for Geosat Follow-On $(G F O)$ it is $-2.0 \mathrm{~mm} \mathrm{yr}^{-1}$; and in TOPEX/Jason-1, as computed here, it is $3.0 \mathrm{yr}^{-1}$.] One purpose of this removal is to separate the required shift in the global mean from that imposed by the altimetric data, so as to understand the degree to which the latter has independent support. (The possibility of a trend is included in the error estimates for the altimetric fits.)

A number of estimates of the subglobal average rate of sea level change and its causes exist in the literature. Table 4 displays a partial listing of existing estimates for the period at the end of the twentieth century. Again, none of the datasets is global, either in latitudelongitude or depth. Averages can be taken over the whole of the ocean represented by the model, but even that, in the present configuration, is not truly global, as the Arctic and some shallow water areas are absent.

In the ECCO-GODAE system, there are three methods for computing the total freshwater added. From estimated:1) $\mathcal{E}=E-P-R$;2) changed mean salinity; and 3) changed halosteric value, $h_{S}$ times the Munk multiplier of 36.7. Among the boundary conditions listed in Table 2 only versions 2 and 6 here produce agreement among the three calculations, and as 2 was used in the optimization, it is those values (consistent with those from 6) that we quote here, acknowledging, however, that this form of boundary condition can generate spurious circulations (Huang 1993), and ultimately 6 must be used.

Trends are computed both from the monthly global spatial averages of the fields and as the monthly average of the trends computed at each grid point. Numerically, the trends are identical, but the standard errors are much reduced in the former (see the discussion about forming averages in appendix A). Over the $12 \mathrm{yr}$ of analysis, the model is seen to be warming and becoming fresher. The net temperature change calculated here is equivalent to about $0.5 \pm 0.1 \mathrm{~mm} \mathrm{yr}^{-1}$ and is roughly the same as the values found by Antonov et al. (2005) and Ishii et al. (2006), but smaller than the others shown in Table 4. The freshening of the model is equivalent to $1.1 \pm 0.04 \mathrm{~mm} \mathrm{yr}^{-1}$ mass addition (halosteric change of about $0.03 \mathrm{~mm} \mathrm{yr}^{-1}$ ). These numbers are generally consistent with others previously published. Figure 16 shows the monthly averages from the entire model domain. The considerable degree of interannual variability, including a maximum during the 1998 El Niño episode, is apparent as is a recent decline. CN2004 show a similar plot, but one which differs in detail, especially in the somewhat different behavior in 2001. Their altimetric total value of about $2.7 \mathrm{~mm} \mathrm{yr}^{-1}$ (prior to the ocean volume correction) is larger than our total of about $1.6 \mathrm{~mm} \mathrm{yr}^{-1}$ made independently of the altimetric trends. No inference is drawn here about the relative accuracy of these values. Figure 16 displays the vertically integrated temperature, salinity, and bottom pressure contributions. Taken at face value, the interannual changes in $\eta$ are dominated by salinity, rather than temperature, and conceivably represent fluctuations in continental ice volume or $\mathcal{E}$ more generally.

The spatial averages are fragile. To demonstrate this conclusion, Fig. 17 shows the spatially averaged trends in the ECCO-GODAE results as the southernmost boundary of the area of averaging is moved northward in $10^{\circ}$ increments. That the magnitude and even the sign of the mean trend changes shows the dependence of subglobal averages on the behavior in the Southern Ocean, where the data coverage is slightest.

Because the abyssal ocean has not had time to respond to the estimated atmospheric forcing, the ocean model is very unlikely to be in equilibrium with the model atmosphere. For example, if the model abyssal ocean is too cool relative to modern atmospheric forcing, a net warming will continue to bring the deep values up to consistency - and this would take thousands of model years. In particular, heating through the sea floor is not present in the calculation; the Adcroft et al. 


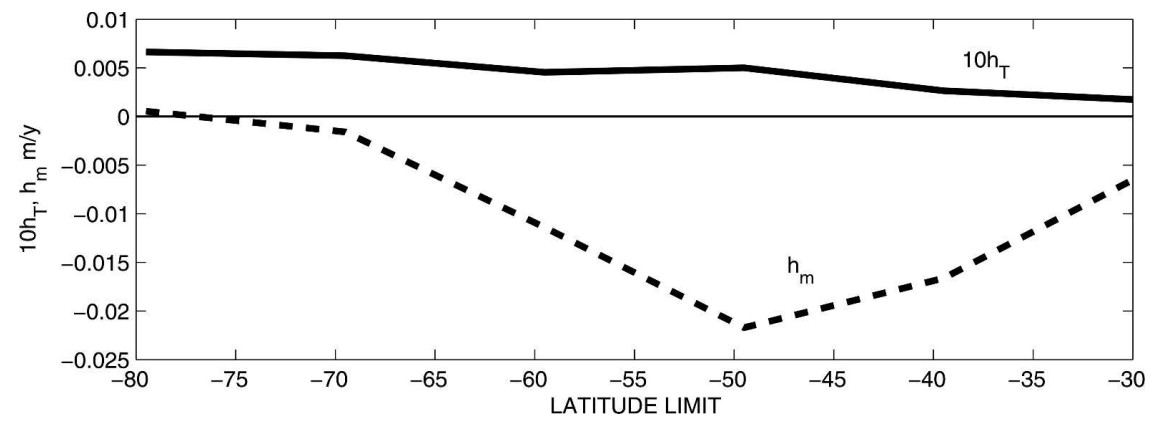

FIG. 17. Spatial-mean thermosteric $\left(h_{T}\right.$, solid) and mass height trends $\left(h_{m}\right.$, dashed) from the optimization estimates as a function of the southernmost boundary of integration, at $10^{\circ}$ intervals. Note that plot is of $10 h_{T}$. Averages, particularly $h_{m}$, are sensitive functions of the position of the southern boundary position.

(2001) estimate implies a required bottom water warming of about $1{ }^{\circ} \mathrm{C}$, which in the current configuration must be supplied from above-leading to a spurious intake of heat over long times.

With the exception of the Carton et al. (2005) results, and a few model-only calculations (Hansen et al. 2005; Barnett et al. 2001), most estimates have been made from interpolation, extrapolation, and integration of the subglobal historical measurements of in situ temperature and/or salinity, or in the last $12 \mathrm{yr}$, from altimetry.

As noted, Antonov et al. (2005) computed a thermal contribution over the period 1955-2003 above $700 \mathrm{~m}$ of about $0.3 \mathrm{~mm} \mathrm{yr}^{-1}$ (but see other values in Table 4). Although there are major problems connected with comparing a trend over $50 \mathrm{yr}$ with one measured only over 12 or 13, the large discrepancy between the Antonov et al. (2005) value and the one inferred both from tide gauges in the earlier period, and altimetry in the later, has led to debate over relative role in the globalmean rise of the freshwater input (Munk 2002, 2003; Miller and Douglas 2004). Some problems exist with the inference, as laid out by Munk (2002, 2003), including an apparent contradiction between earth polar motion and rotation data, and inferences about the volume of melting continental ice. [Mitrovica et al. (2006) propose that much of the difficulty would disappear with use of a corrected postglacial rebound model, and it is probably also true that none of the apparent conflicts exceeds the errors in the observations.]

\section{Discussion and summary}

Using about $2.1 \times 10^{9}$ observations of many different types, all individually weighted, during the period 19922004 and a $1^{\circ}$ horizontal resolution, 23-layer general circulation model, estimates are made of regional trends in global sea level. The spatial structures are a complex, dynamical phenomenon involving both the regional response to forcing patterns $(\mathcal{H}, \mathcal{E}$, and wind stress) as well as water movements dependent most directly on the wind stress and its curl. Patterns of regional sea level change are robust results of the estimation process and are approximately consistent with those inferred from the altimeter measurements alone, but differ in important details. A substantial fraction of the thermal contribution to sea level change is compensated by opposing salinity shifts, preserving the local $T-S$ relations. Temperature and salinity contributions to density have a spatial correlation of about 0.5 , so that about $25 \%$ of the temperature variance contribution to the density change is compensated by salinity. These compensating motions are most readily explained as arising from primarily adiabatic movements, horizontally and vertically, of the quasi-permanent oceanic general circulation structures - the thermocline and gyres, probably largely controlled by the wind field. Stammer (1997) globally, and others working regionally, have diagnosed interannual variability in terms of steric changes and wind driving. It is not known whether the trendlike changes seen here have a physics in common with the shorter period changes, nor whether any of the regional trends is truly secular. Temperature and salinity trends below the main thermocline are important but not dominant except, apparently, in the Southern Ocean. Their importance can be expected to grow as the duration increases and abyssal waters slowly change, calling attention for the need to measure the abyss for future-generation calculations of ongoing climate-scale changes.

Given the long memory times in the ocean, the regional patterns of change estimated here for the period 1993-2004 are likely in part the result of forcing and internal changes occurring well before this interval. 
Fluctuations long prior to the estimation interval are capable of producing regional shifts remote in both space and time from the initial triggers. Regional sea level change studies are thus bound tightly to shifts in the general circulation on all time and space scales.

The Southern Ocean contribution remains problematic, primarily because there are so little historical data from that region, but also because, from a modeling point of view, the unusual importance of eddy physics is incompletely accounted for. Notice in particular the inferred large relative sea level rise in Fig. 2 in the Southern Ocean as compared to Fig. 1. Gille (2002) pointed out a long-term warming trend in the Southern Ocean, but the observations remain extremely sparse, although that is now changing with the Argo and elephant seal profiles in the upper oceans. Note, however, that the formal error estimates in Fig. 3 imply the large changes in the present estimates are unlikely to be statistically significant. To the extent that a sea level rise exists in the Southern Ocean, it reduces the contribution to the mean from other latitudes. The ocean above about $850 \mathrm{~m}$ dominates the thermal expansion and salinity changes, but the contributions below that depth are not negligible, and are expected to rise as time passes and the deep ocean begins to respond more strongly to changes in surface forcing. Another concern in the Southern Ocean, as with high northern latitudes, is the use of incomplete models of sea ice formation and its interaction with the ocean, including problems with the salinity budgets and the pressure loading of the ice.

Although intense interest exists in the global average value of sea level change, and the plausible inference of an average rise, actually obtaining a useful result proves extremely difficult. If errors in the altimetric data are fully understood (not clear), estimates of an average rise near $3 \mathrm{~mm} \mathrm{yr}^{-1}$ (e.g., CN2004) are sensible, but currently untestable against in situ datasets. Several problems exist: Figs. 1 or 2 show the great regional variability in trend values, sometimes up to two orders of magnitude larger than the apparent spatial mean. In addition to remaining questions about altimetric error sources (e.g., geocenter movement), the sampling errors involving temporal aliasing and missing highlatitude coverage need to be better understood. In situ data are never truly global, have strong seasonal biases, are primarily confined to the upper ocean, and likely contain systematic errors of various types. Meteorological estimates from the so-called reanalyses are unconstrained in terms of global heat and freshwater budgets. Conversions from halosteric to mass components in sea level necessary to compute net freshwater inputs from salinity changes place very strong requirements (Munk 2003) on the accuracy of the mean salinity change and on the equation of state, particularly in models where various simplifications are made. Models based upon the Boussinesq approximation (the majority, as here) are susceptible to otherwise negligible small errors such as the use of source terms in the near-surface salinity conservation equation, among others.

At best, the determination and attribution of globalmean sea level change lies at the very edge of knowledge and technology. The most urgent job would appear to be the accurate determination of the smallest temperature and salinity changes that can be determined with statistical significance, given the realities of both the observation base and modeling approximations. Both systematic and random errors are of concern, the former particularly, because of the changes in technology and sampling methods over the many decades, the latter from the very great spatial and temporal variability implied by Figs. 2, 6, and 8 . It remains possible that the database is insufficient to compute mean sea level trends with the accuracy necessary to discuss the impact of global warming - as disappointing as this conclusion may be. The priority has to be to make such calculations possible in the future.

Acknowledgments. Our many ECCO and ECCOGODAE partners contributed to this work, supported in part by the National Ocean Partnership Program (NASA, NOAA) and additional NASA funding. Computations were done at the NOAA/Geophysical Fluid Dynamics Laboratory and at the National Center for Atmospheric Research (NCAR). Charmaine King did much of the computation and endless plotting. We thank Dr. Bruce Warren for discussion of hydrographic sampling errors. Helpful comments on an early draft were provided by P. Huybers, J. Willis, J. Lyman, and J. Church. Further input by B. Arbic, J. Hansen, A. Cazenave, D. Stammer, G. Johnson, and P. Woodworth, as well as two anonymous reviewers, was very useful. The efforts of the many people who obtained the observational products used here is gratefully acknowledged.

\section{APPENDIX A}

\section{Calculating Averages}

Both the model output and the altimetric data are put onto a $1^{\circ} \times 1^{\circ}$ grid and that raises the question of how to form global average values of any variable $y_{i}$, where $i$ denotes a particular grid point. Among several possibilities are 1) uniformly weighted, $\tilde{m}_{1}=1 / N \Sigma_{1}^{N} y_{i}$; 2) area weighted, $\tilde{m}_{2}=\Sigma A_{i} y_{i} / \Sigma A_{i}=\Sigma A_{i}^{\prime} y_{i}$, where $A_{i}$ is the area corresponding to grid cell $i$, and $A_{i}^{\prime}$ is its frac- 
tional value; and 3) minimum variance, $\tilde{m}_{3}=\Sigma\left(y_{i} / \sigma_{i}^{2}\right) /$ $\Sigma\left(1 / \sigma_{i}^{2}\right)$, where $\sigma_{i}^{2}$ is the variance in time of $y_{i}$.

Areas within the model and for the gridded altimetry vary as the cosine of the latitude. Variances are spatially very inhomogeneous as they are usually dominated by the eddy noise, and which has a very strong positional dependence (Fig. 5). The uncertainty of $\tilde{m}_{1}$ would conventionally be computed as $\sigma^{2} / N$, where $\sigma^{2}$ is an estimate of the global-mean variance, which for $\tilde{m}_{2}$ would be $\Sigma_{i}\left[A_{i}^{\prime} y_{i}-(1 / N) \Sigma_{j}\left(A_{j}^{\prime} y_{j}\right)\right]^{2}$ and for $\tilde{m}_{3}$ is $P_{3}=$ $\left[\sum_{i=1}^{N}\left(1 / \sigma_{i}^{2}\right)\right]^{-1}$. In some papers, it is unclear which average has been used.

Because of the area and variance changes with position, these averages do not coincide and the choice must be physically based. In a homogeneous ocean, one would have $y_{i}=m+n_{i}$; that is, the value at each grid point is the global mean (the "eustatic" component) plus zero-mean noise of variance $\sigma_{i}^{2}$. In this case (e.g., Wunsch 2006, p. 133) the minimum variance estimate would be chosen. On the other hand, in a physically inhomogeneous ocean, the means of trends in different areas (high latitudes, western boundary currents, etc.) are expected to be different and the quantity of interest is not the spatial mean per se, but the amount of water added or removed globally, that is, $\tilde{m}_{2} \Sigma A_{i}$, and $\tilde{m}_{2}$ is used here except where otherwise specified. The value $\tilde{m}_{1}$ would be used if the noise error in $y_{i}$ is independent of the area represented, for example, if the uncertainty at high latitudes where the areas are smallest was proportionally small (possibly true of altimetric data, untrue for hydrographic data, and fundamentally unknown for model results). Several other averages, involving area/volume and variance weighting, including that of the expected trend structures, can also be defined. In the figures displaying regional variations, the differences between removing different $\tilde{m}_{i}$ are visually almost undetectable.

Calculation of model spatial-mean trends also requires some comment. There are two obvious ways to compute the trends in any variable, $y_{i}(t)$, where $i$ is a grid point and $t$ represents monthly time steps: 1) Calculate the trend in the monthly mean values at each grid point and form their area-weighted global average. 2) Form a global average $\bar{y}(t)=\Sigma_{i} A_{i}^{\prime} y_{i}(t)$ and calculate the 12-yr trend from these values. The two trends should be (and are) identical; what differs is the estimate of the errors, which for method 1 has been calculated as the standard errors of the $y_{i}$ averages. In general, the solution is so noisy that method 1 produces values that are not statistically significant. In contrast, trends computed from method 2 are significant (assuming near-Gaussian statistics and month-to-month independence of the globally summed noise) and are the values we use. The difference between the error outcomes of methods 1 and 2 implies that the monthly variability in properties such as sea level has a highwavenumber character that is effectively suppressed by the global summation. The formation of spatial averages involves a competition between the effects of smoothing, which decreases the final variance, and a reduction in degrees of freedom, which increases it. Here the variance reduction dominates. Much of the remaining uncertainty in estimates (method 2) arises from the predictable part of the residual annual cycle in some variables, and thus the formal errors could be further reduced, although we do not take that step here.

\section{APPENDIX B}

\section{Data Types}

\section{a. Altimetry}

Altimetric data (CN2004) are widely accepted as providing the best available estimate of mean global sea level rise. Errors in the time-varying components of altimetric datasets are complex and not wholly quantified (see, e.g., Chelton et al. 2001; Ponte et al. 2007; and the collection of papers in the special issues of Marine Geodesy, Vol. 27, Nos. 1-4). Although the altimetric result is a plausible one, the system is clearly being pushed to the edge of the state of the art (also see Nerem 1995, 1997 for discussion of the difficulties), and the original designers of the TOPEX/Poseidon mission never contemplated using the observations in this way, as the a priori error estimates were much too large.

In the estimation procedure used here, the errors are assumed to be adequately described by Ponte et al. (2007) and are a complicated function of geographical position, displayed in Fig. 5, which is dominated by the high wavenumber variability. Their analysis does not include the annual cycle, nor other lower-frequency variability possibly confounding trend determination, nor the spatial correlations in the errors.

Leuliette et al. (2004) discuss the global calibration and they suggest a mean trend uncertainty of $\pm 0.4 \mathrm{~mm}$ $\mathrm{yr}^{-1}$. Fernandes et al. (2006) review many of the sources of error in the altimetric system. Their discussion is complicated and their paper should be consulted for details, keeping in mind that their analysis was regional, not global, nonetheless providing useful insight into the issues. They find that different corrections for the sea state bias produce regional trends varying between about 0.6 and $1.3 \mathrm{~mm} \mathrm{yr}^{-1}$, the latter in the subArctic. Radiometer (atmospheric water vapor) drift corrections, the nature of the inverted barometer cor- 
rection, and orbit errors all contribute. Lavallée et al. (2006) suggest that there are significant movements in the position of the geocenter (the center of mass of the terrestrial reference system to which the orbits are referred). Although their focus is on the annual cycle, it is clear that a secular trend in the geocenter, if one exists, could produce an apparent mean sea level change, depending upon the direction (the effect would vanish on a water-covered earth).

The mean subglobal rate increases to over $3 \mathrm{~mm} \mathrm{yr}^{-1}$ according to $\mathrm{CN} 2004$ if a further correction for postglacial rebound is introduced [the volume of the ocean being inferred to be increasing with time; see Peltier (2001)]. An accuracy estimate for this systematic effect is not known to us and significant differences exist among rebound models.

The major calibration standard for the altimetry lies with the tide gauges (Mitchum 1998; Church et al. 2001), but which suffer from a poor geographical distribution and susceptibility to remaining errors in postglacial rebound models. At the present time, a global altimetric mean estimated rise of $2.5-3 \mathrm{~mm} \mathrm{yr}^{-1}$ is widely accepted as being the most reliable value, but the error estimates are relatively large and complex, and further independent evidence supporting the altimetric values would be welcome.

\section{b. Hydrography}

Existing estimates of thermal and freshwater contributions to sea level change, regional and global, have been based directly on in situ hydrographic measurements. The main problems concern the space-time sampling and the possibility of systematic errors.

Worthington (1981), in his attempt to define the water mass properties of the World Ocean, excluded much of the data as being insufficiently accurate (largely determined by failure of deep measurements to converge to known tight $T-S$ relations). His Fig. 2.1 showed his estimate, as of 1977 , of $5^{\circ}$ squares where he believed there was at least one adequate hydrographic station covering the whole water column. The entire Pacific Ocean was nearly void, and the Southern Hemisphere was almost unmeasured. (The Southern Ocean appeared in his classification as well observed, but the data were primarily from the one-time visit of the R/V Eltanin.)

In the intervening years there have been a number of developments including attempts [notably in the World Ocean Circulation Experiment (WOCE)] to greatly improve the coverage, and the "data mining" activities described by Levitus et al. (2001) to salvage otherwise unavailable data. The Pacific Ocean is no longer primarily blank. The modern measurements, now includ- ing Argo profiles (Gould et al. 2004) to $2000 \mathrm{~m}$ in the last three years, although of great value for future attempts to define trends, are not directly useful in determining historical trends. At best, one can ask, What is the accuracy with which the recent data define the present mean temperatures and salinities?

The data-mining results are difficult to interpret because of the complexity of the potential underlying errors. To the extent that errors in temperature and salinity are truly random, the more data the better-as the random errors will tend to diminish when averaging the growing database. But if the errors are systematic, the addition of further data can degrade the averages. No attempt is made here to evaluate the measurement errors in the World Ocean Atlas climatologies (Levitus et al. 2001). In their new climatology, which is used in the present estimates below $300 \mathrm{~m}$, Gouretski and Koltermann (2004) discarded about $40 \%$ of the data used by Levitus et al. (2001) in a culling closer to Worthington's (1981) judgment.

Forget and Wunsch (2007) discuss the coverage of the Levitus et al. (2001) dataset at $300 \mathrm{~m}$ for temperature and salinity where there were at least four measurements in a $1^{\circ}$ square. Much of the Southern Hemisphere remains unsampled in both temperature and salinity, as the Northern Hemisphere in salinity at this shallow depth. Greater depths have a coverage that degrades rapidly.

The number of values available each month in the World Ocean Atlas is shown in Fig. B1. Note, among other issues, a visually prominent annual cycle in the number of samples. A well-known electrical engineering result is that periodic sampling of a periodic signal (the annual cycle) can produce complex rectified signals (e.g., Wozencraft and Jacobs 1965). A full discussion of the adequacy of error estimation in any of the available global climatologies is a major undertaking, depending as it does upon evaluating the interpolation and extrapolation rules used by the various authors to fill the very large data gaps. That very little data, altimetry included, exists in the Southern Ocean is a particular concern in all published subglobal averages.

A full discussion of the sampling problem is an elaborate exercise, largely because the a priori variance of temperature and salinity measurements is a very strong function of both horizontal position and depth. If the ocean were statistically homogeneous, failure to sample significant regions would have minor influence on computation of the mean. As it is, the general lack of data in the Southern Ocean until very recently is of especial concern because it may well be behaving differently than the rest of the World Ocean (for context, about $18 \%$ of both the ocean area and volume lie poleward of 


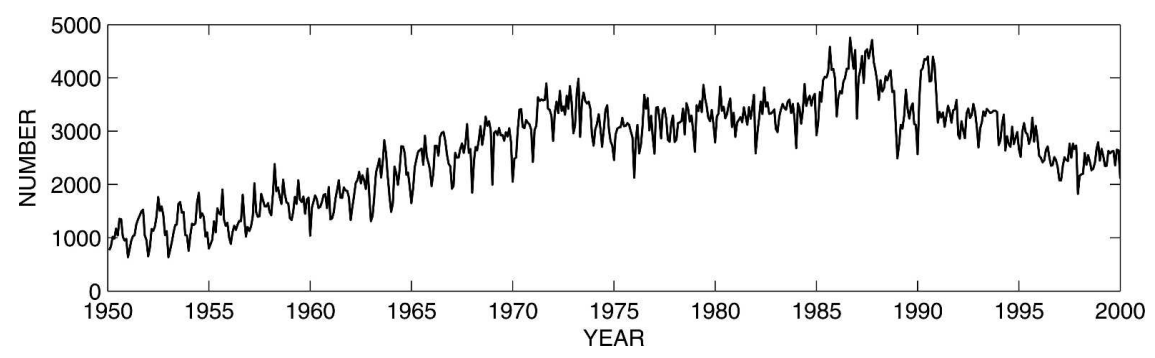

FIG. B1. Numbers of temperature measurement positions reported in the World Ocean Atlas since 1950. Note the seasonal cycle in sample numbers.

about $45^{\circ} \mathrm{S}, 25 \%$ poleward of $35^{\circ} \mathrm{S}$, and omitting these from averages can be very important; see Fig. 17).

\section{1) LOWER BOUNDS ON THE SAMPLING ERRORS}

The space-time inhomogeneities in sampling of the ocean by in situ hydrography raise difficulties in determining errors in the apparent mean trends. Gregory et al. (2004) and AchutaRao et al. (2006) instead sampled models to mimic the Levitus et al. (2001) calculation and found large discrepancies between global and hemispheric averages, including, in the former, sign reversals [somewhat in conflict with the results of Barnett et al. (2001)]. Harrison and Carson (2007) discuss the great difficulties in inferring global upper ocean averages from the data after 1950 and call attention to the need for far better understanding of the accuracies of quoted subglobal averages.

We will not pursue this subject here except to note that much of the outcome depends upon the accuracy of assumed spatial statistics and in particular, whether the covariances used apply also to such poorly sampled regions as the Southern Ocean. [Willis et al. (2004) used the Zang and Wunsch (2001) spatial covariances, which were derived from Northern Hemisphere data alone. Their accuracy in the Southern Ocean has not been tested.]

\section{2) Technology shifts}

Evolution of the measurement technology is another major concern in determining the historical trends. In the period discussed, for example, by Antonov et al. (2005), the measurement of salinity was done by laboratory determination of the salt content in water samples collected, initially, by Nansen bottles, and then by rosette samplers combined with continuously profiling conductivity cells. Laboratory measurement techniques shifted from titrations to early conductivity devices to the Schleicher-Bradshaw salinometer system and salinity was redefined to follow the changing methodology (see the discussion by Worthington 1981). The redefinitions were very carefully constructed, so that in a perfect world the changing methods would not lead to fictitious trends. Several practical problems creep in, however. In particular, unless great care is taken, systematic errors can easily occur. For example, many cruises did not carry salinity measuring equipment or skills, and the sample bottles were brought ashore for delayed measurement. Recognition, outside the small group of expert hydrographers, that evaporation from such bottles was significant came only very late in the day, and as evaporation can only increase salinities, it is a strong mechanism for generation of systematic errors in inadequately sealed sample bottles. ${ }^{\mathrm{B} 1}$

Equivalent issues occur for temperature. In particular, the technology changed from reversing thermometers to salinity-temperature-depth (STD) and then conductivity-temperature-depth (CTD) devices, and pressure (depth) measurements shifted from the use of protected and unprotected reversing thermometers to strain gauges. Bathythermographs evolved from purely mechanical-tethered ones to free-falling electronic types. Errors in depth inference would translate into apparent temperature changes. For example, and as discussed by Gouretski and Koltermann (2004), sparse use of protected reversing thermometers led to the assignment of many values to intended standard depths rather than measured ones. We are unaware, however, of any quantitative discussion of possible systematic errors owing to the hydrographic station technology changes [but see Gouretski and Jancke (2001); Antonov et al. (2002) report that they could find no statistically significant differences for the periods of differing technology — a reassuring, if surprising, result]. For XBT data, there is a consensus (e.g., Lombard et al. 2006) that changes or misapplications in the fall-rate algorithm have given rise to spurious trend differences in some published analyses, and all observing systems

\footnotetext{
${ }^{\mathrm{B} 1}$ We thank B. Warren for discussion of the salinity sampling problem.
} 
inevitably are susceptible to systematic errors at some level (see also Gouretski and Koltermann 2007).

\section{c. Forcing imbalances and surface boundary conditions}

One approach, in principle, to estimating sea level rise would be to calculate it from the net heating and net estimated evaporation minus precipitation minus runoff $(\mathcal{E}=E-P-R)$ from the atmospheric reanalyses. The initial estimate for the boundary forcing of the ECCO-GODAE model is taken from the NCEPNCAR "reanalysis" of Kalnay et al. (1996), and wind stress, freshwater, and enthalpy fluxes are part of the system control vector, and thus subject to adjustment to render the model consistent with the data. In the case of the meteorological forcing, the prior weights are an estimate of the degree to which the atmospheric variables are likely to be in error and thus expected to change. This atmospheric reanalysis poses several problems.

The Kalnay et al. (1996) estimate and its subsequent upgrades were computed from a weather forecast model and data assimilation method. No global constraints were applied, and thus considerable imbalances in the global water and heat budgets are present. For example, in one NCEP-NCAR release, the net estimated $\varepsilon$ to the ocean was found to average $6 \mathrm{~cm}$ of water $\mathrm{yr}^{-1}$, and the net heating of the ocean exceeded $2 \mathrm{~W} \mathrm{~m}^{-2}$ (see P. Heimbach and C. King 2006, unpublished manuscript). Béranger et al. (2006) found differences extending over more than $10^{\circ}$ of latitude exceeding $1 \mathrm{~m} \mathrm{yr}^{-1}$ in various published zonal precipitation climatologies. Global imbalances have no known negative influence on weather forecasting skill and so have attracted little attention. For our purposes, they could be disastrous.

Considerable controversy exists surrounding the net input of freshwater to the ocean, involving as it does determining the net loss of continental and sea ice as well as runoff and water storage (e.g., Rignot and Thomas 2002; Cazenave 2006). Because of the debate over the sign of net ice volume changes, and the way in which weights are changed in the calculations to guide the minimization, it is very difficult to rigorously assign an a priori net input of freshwater. Effectively, over the $13 \mathrm{yr}$, the prior estimate is zero with an error estimate of $\pm 0.16 \mathrm{~mm} \mathrm{yr}^{-1}$. It is estimated a priori that the global heating by the atmosphere is $1 \mathrm{~W} \mathrm{~m}^{-2}$ (e.g., Barnett et al. 2001; Hansen et al. 2005, from coupled models) with an unknown uncertainty, but estimated by us initially as $\pm 0.6 \mathrm{~W} \mathrm{~m}^{-2}$ [inferred from Hansen et al. (2005), but clearly very crude]. Note that $1 \mathrm{~W} \mathrm{~m}^{-2}$ heating corresponds to a sea level rise of approximately 1.3 $\mathrm{mm} \mathrm{yr}^{-1}$.
Achieving balanced freshwater fluxes is a critical prerequisite when forcing the model with freshwater boundary conditions, rather than the unphysical virtual salt flux boundary conditions (Huang 1993), as well as avoiding restoring sea surface salinity, which might have further spurious effects. P. Heimbach and C. King (2006, unpublished manuscript) summarize freshwater imbalances in the NCEP-NCAR I reanalysis. They find that none of ocean-only $E-P$, or $E-P-R$, or truly global $E-P$ are balanced. The ECCO-GODAE state estimates, which used virtual salt flux boundary conditions through version 2.199, were able to reduce the imbalance somewhat, but not to a degree sufficient to avoid severe distortions to the signal in sea surface elevation.

The estimation framework permits addressing deficiencies in the $E-P$ fluxes. We require the global (over ocean) $\mathcal{E}$ to approximately vanish over the 13 -yr period via a suitable extra term in the misfit function. The gradient of the misfit with respect to $\mathcal{E}$ provides the necessary adjustments needed, while ensuring that the model minus observation misfits are not degraded. This term has been applied starting with the use of freshwater flux boundary conditions in v2.200. In addition, a global mean and trend in $\mathcal{E}$ has been removed in v2.200 as a first guess to speed up the convergence.

\section{APPENDIX C}

\section{Model Issues}

The MITgcm, in its existing ECCO-GODAE configuration, like most ocean models, employs the Boussinesq approximation. Net heating or cooling of a Boussinesq model affects the spatial-mean bottom pressure, but leaves the spatial-mean sea surface unchanged. In contrast, adding or subtracting freshwater affects both the mean sea surface elevation and the mean bottom pressure. Here, following Greatbatch (1994), the spatial-mean bottom pressure change owing to changes in mean density is converted into an equivalent spatialmean sea level rise. It is important to note, however (see Dewar 1998; McDougall et al. 2002; Huang and Jin 2002; Losch et al. 2004), that other approximations are buried in the Boussinesq numerics and their influence on regional and global sea level change is obscure.

Another important set of approximations involves the way in which the free surface import and export of freshwater takes place across the model sea surface, a problem that Huang (1993) and others have called attention to. We can identify at least six different surface boundary conditions for freshwater and salt in use in general circulation models (P. Heimbach and J.-M. 
Campin 2006, unpublished manuscript; see Table 2). In regions of sea ice formation and melting, approximations are made to the exchange of salt between ice and ocean, and with the way in which the mass of floating ice is represented in bottom pressures. See, for example, Campin et al. (2004) and Griffies (2004) for further discussion of model approximations at the sea surface. Here, we rely primarily on the system involving a linear free surface and virtual salt flux (number 2 in Table 2) because it produces consistent estimates of the freshwater exchange, which is not true, for example, for system 3.

Many other approximations, including the rendering of continuous partial differential equations as discrete, the parameterizations of eddy flux terms, neglect of seafloor heating, truncated equations of state, etc. underlie all model calculations. The extent to which they produce systematic effects that generate spurious temporal trends in model volume or mass totals is not known, and thus any results from long model integrations should be viewed with caution.

\section{REFERENCES}

AchutaRao, K. M., B. D. Santer, P. J. Gleckler, K. E. Taylor, D. W. Pierce, T. P. Barnett, and T. M. L. Wigley, 2006: Variability of ocean heat uptake: Reconciling observations and models. J. Geophys. Res., 111, C05019, doi:10.1029/ 2005 JC003136.

Adcroft, A., J. R. Scott, and J. Marotzke, 2001: Impact of geothermal heating on the global ocean circulation. Geophys. Res. Lett., 28, 1735-1738.

Antonov, J. I., S. Levitus, and T. P. Boyer, 2002: Steric level variations during 1957-1994: Importance of salinity. J. Geophys. Res., 107, 8013, doi:10.1029/2001JC000964.

,-- , and 2005: Thermosteric sea level rise, 1955-2003. Geophys. Res. Lett., 32, L12602, doi:10.1029/2005GL023112.

Barnett, T. P., D. W. Pierce, and R. Schnur, 2001: Detection of anthropogenic climate change in the world's oceans. Science, 292, 270-274.

Béranger, K., B. Barnier, S. Gulev, and M. Crépon, 2006: Comparing 20 years of precipitation estimates from different sources over the World Ocean. Ocean Dyn., 56, 104-138.

Campin, J.-M., A. Adcroft, C. Hill, and J. Marshall, 2004: Conservation of properties in a free-surface model. Ocean Modell., 6, 221-244.

Carton, J. A., B. S. Geise, and S. A. Grodsky, 2005: Sea level rise and the warming of the oceans in the Simple Ocean Data Assimilation (SODA) ocean reanalysis. J. Geophys. Res., 110, C09006, doi:10.1029/2004JC002817.

Cazenave, A., 2006: How fast are the ice sheets melting? Science, 314, 1250-1252.

—_ and R. S. Nerem, 2004: Present-day sea level change: Observations and causes. Rev. Geophys., 42, RG3001, doi:10.1029/2003RG000139.

Chelton, D. B., J. C. Ries, B. J. Haines, L. L. Fu, and P. S. Callahan, 2001: Satellite altimetry. Satellite Altimetry and Earth Sciences: A Handbook of Techniques and Applications, L.-L. Fu and A. Cazenave, Eds., Academic Press, 1-131.
Church, J., J. M. Gregory, P. Huybrechts, M. Kuhn, K. Lambeck, M. T. Nhuan, D. Qin, and P. L. Woodworth, 2001: Changes in sea level. Climate Change 2001: The Scientific Basis, J. T. Houghton et al., Eds., Cambridge University Press, 639-693.

Curry, R., and C. Mauritzen, 2005: Dilution of the northern North Atlantic Ocean in recent decades. Science, 308, 1772-1774.

Dewar, W. K., 1998: Calculation of pressure in ocean simulations. J. Phys. Oceanogr., 28, 577-588.

Douglas, B. C., M. S. Kearney, and S. R. Leatherman, Eds., 2001: Sea Level Rise: History and Consequences. Academic Press, $232 \mathrm{pp}$

Fekete, B. M., C. J. Vörösmarty, and W. Grabs, 2002: Highresolution fields of global runoff combining observed river discharge and simulated water balances. Global Biogeochem. Cycles, 16, 1042, doi:10.1029/1999GB001254.

Fernandes, M. J., S. Barbosa, and C. Lázaro, 2006: Impact of altimeter data processing on sea level studies. Sensors, 6, 131163.

Forget, G., and C. Wunsch, 2007: Estimated global hydrographic variability. J. Phys. Oceanogr., 37, 1997-2008.

Fu, L.-L., and A. Cazenave, Eds., 2001: Satellite Altimetry and Earth Sciences: A Handbook of Techniques and Applications. Academic Press, 463 pp.

Gille, S. T., 2002: Warming of the Southern Ocean since the 1950s. Science, 295, 1275-1277.

- 2004: How nonlinearities in the equation of state of seawater can confound estimates of steric sea level change. J. Geophys. Res., 109, C03005, doi:10.1029/2003JC002012.

Gould, J., and Coauthors, 2004: Argo profiling floats bring new era of in situ ocean observations. Eos, Trans. Amer. Geophys. Union, 85, 170, 190-191.

Gouretski, V. V., and K. Jancke, 2001: Systematic errors as the cause for an apparent deep water property variability: Global analysis of the WOCE and historical hydrographic data. Prog. Oceanogr., 48, 337-402.

— , and K. P. Koltermann, 2004: WOCE global hydrographic climatology: A technical report. Berichte des Bundesamtes für Seeschifffahrt und Hydrographie 35, 52 pp. and two CDROMs.

_ and 2007: How much is the ocean really warming? Geophys. Res. Lett., 34, L01610, doi:10.1029/2006GL027834.

Greatbatch, R. J., 1994: A note on the representation of steric sea level in models that conserve volume rather than mass. $J$. Geophys. Res., 99, 12 767-12 771.

Gregory, J. M., H. T. Banks, P. A. Stott, J. A. Lowe, and M. D. Palmer, 2004: Simulated and observed decadal variability in ocean heat content. Geophys. Res. Lett., 31, L15312, doi:10.1029/2004GL020258.

Griffies, S. M., 2004: Fundamentals of Ocean Climate Models. Princeton University Press, $518 \mathrm{pp}$.

Hansen, J., and Coauthors, 2005: Earth's energy imbalance: Confirmation and implications. Science, 308, 1431-1435.

Harrison, D. E., and M. Carson, 2007: Is the World Ocean warming? Upper-ocean temperature trends: 1950-2000. J. Phys. Oceanogr., 37, 174-187.

Huang, R. X., 1993: Real freshwater flux as a natural boundary condition for the salinity balance and thermohaline circulation forced by evaporation and precipitation. J. Phys. Oceanogr., 23, 2428-2446.

, and X. Jin, 2002: Sea surface elevation and bottom pressure anomalies due to thermohaline forcing. Part I: Isolated perturbations. J. Phys. Oceanogr., 32, 2131-2150. 
Ishii, M., M. Kimoto, K. Sakamoto, and S.-I. Iwasaki, 2006: Steric sea level changes estimated from historical ocean subsurface temperature and salinity analyses. J. Oceanogr., 62, 155-170.

Jackett, D. R., and T. J. McDougall, 1995: Minimal adjustment of hydrographic profiles to achieve static stability. J. Atmos. Oceanic Technol., 12, 381-389.

Jenkins, G. M., and D. G. Watts, 1968: Spectral Analysis and Its Applications. Holden-Day, 525 pp.

Kalnay, E., and Coauthors, 1996: The NCEP/NCAR 40-Year Reanalysis Project. Bull. Amer. Meteor. Soc., 77, 437-471.

Köhl, A., D. Stammer, and B. Cornuelle, 2007: Interannual to decadal changes in the ECCO global synthesis. J. Phys. Oceanogr., 37, 313-337.

Lavallée, D. A., T. van Dam, G. Blewitt, and P. J. Clarke, 2006: Geocenter motions from GPS: A unified observation model. J. Geophys. Res., 111, B05405, doi:10.1029/2005JB003784.

Leuliette, E. W., R. S. Nerem, and G. T. Mitchum, 2004: Results of TOPEX/Poseidon and Jason-1 calibration to construct a continuous record of mean sea level. Mar. Geod., 27, 79-94.

Levitus, S., J. I. Antonov, J. Wang, T. L. Delworth, K. W. Dixon, and A. J. Broccoli, 2001: Anthropogenic warming of Earth's climate system. Science, 292, 267-270.

Lombard, A., A. Cazenave, P.-Y. LeTraon, S. Guinehut, and C. Cabanes, 2006: Perspectives on present-day sea level change: A tribute to Christian le Provost. Ocean Dyn., 56, 445-451.

Losch, M., A. Adcroft, and J.-M. Campin, 2004: How sensitive are coarse general circulation models to fundamental approximations in the equations of motion? J. Phys. Oceanogr., 34, 306-319.

Lyman, J. M., J. K. Willis, and G. C. Johnson, 2006: Recent cooling of the upper ocean. Geophys. Res. Lett., 33, L18604, doi:10.1029/2006GL027033.

Marshall, J., A. Adcroft, C. Hill, L. Perelman, and C. Helsey, 1997: A finite-volume, incompressible Navier-Stokes model for studies of the ocean on parallel computers. J. Geophys. Res., 102, 5753-5766.

McDougall, T. J., R. J. Greatbatch, and Y. Y. Lu, 2002: On conservation equations in oceanography: How accurate are Boussinesq ocean models? J. Phys. Oceanogr., 32, 1574-1584.

Miller, L., and B. C. Douglas, 2004: Mass and volume contributions to twentieth-century global sea level rise. Nature, $\mathbf{4 2 8}$, 406-409.

Mitchum, G. T., 1998: Monitoring the stability of satellite altimeters with tide gauges. J. Atmos. Oceanic Technol., 15, 721730 .

Mitrovica, J. X., M. E. Tamisiea, J. L. Davis, and G. A. Milne, 2001: Recent mass balance of polar ice sheets inferred from patterns of global sea-level change. Nature, 409, 1026-1029.

_ , J. Wahr, I. Matsuyama, A. Paulson, and M. E. Tamisiea, 2006: Reanalysis of ancient eclipse, astronomic and geodetic data: A possible route to resolving the enigma of global sealevel rise. Earth Planet Sci. Lett., 243, 390-399.

Munk, W., 2002: Twentieth century sea level: An enigma. Proc. Natl. Acad. Sci. USA, 99, 6550-6555.

-, 2003: Ocean freshening, sea level rising. Science, 300, 20412043.
Nerem, R. S., 1995: Global mean sea level variations from TOPEX/POSEIDON altimeter data. Science, 268, 708-710.

- 1997: Global mean sea level change: Correction. Science, 275, 1053.

Patullo, J. G., W. H. Munk, R. Revelle, and E. Strong, 1955: The seasonal oscillation in sea level. J. Mar. Res., 14, 88-155.

Peltier, W. R., 2001: Global glacial isostatic adjustment and modern instrumental records of relative sea level history. Sea Level Rise: History and Consequences, B. C. Douglas, M. S. Kearney, and S. P. Leatherman, Eds., Academic Press, 65-95.

Pierce, D. W., T. P. Barnett, K. M. Achutarao, P. J. Gleckler, J. M. Gregory, and W. M. Washington, 2006: Anthropogenic warming of the oceans: Observations and model results. $J$. Climate, 19, 1873-1900.

Plag, H.-P., 2006: Recent relative sea-level trends: An attempt to quantify the forcing factors. Philos. Trans. Roy. Soc. London, A364, 821-844.

Ponte, R., C. Wunsch, and D. Stammer, 2007: Spatial mapping of time-variable errors in Jason-1 and TOPEX/Poseidon sea surface height measurements. J. Atmos. Oceanic Technol., 24, 1078-1085.

Rignot, E., and R. H. Thomas, 2002: Mass balance of polar ice sheets. Science, 297, 1502-1506.

Stammer, D., 1997: Steric and wind-induced changes in TOPEX/ POSEIDON large-scale sea surface topography observations. J. Geophys. Res., 102, 20 987-21 010.

- A. Köhl, and C. Wunsch, 2007: Impact of accurate geoid fields on estimates of the ocean circulation. J. Atmos. Oceanic Technol., 24, 1464-1478.

Wenzel, M., and J. Schröter, 2007: The global ocean mass budget in 1993-2003 estimated from sea level change. J. Phys. Oceanogr., 37, 203-213.

Willis, J. K., D. Roemmich, and B. Cornuelle, 2004: Interannual variability in upper ocean heat content, temperature, and thermosteric expansion on global scales. J. Geophys. Res., 109, C12036, doi:10.1029/2003JC002260.

_, J. M. Lyman, G. C. Johnson, and J. Gilson, 2007: Correction to "Recent cooling of the upper ocean." Geophys. Res. Lett., 34, L16601, doi:10.1029/2007GL030323.

Woodworth, P., J. M. Gregory, and R. J. Nicholls, 2004: Long term sea level changes and their impacts. The Sea, A. R. Robinson and K. Brink, Eds., Biological-Physical Interactions in the Sea, Vol. 12, Harvard University Press, 717-752.

Worthington, L. V., 1981: The water masses of the world ocean: Some results of a fine-scale census. Evolution of Physical Oceanography, B. A. Warren and C. Wunsch, Eds., MIT Press, 42-69.

Wozencraft, J. M., and I. M. Jacobs, 1965: Principles of Communication Engineering. Wiley, 720 pp.

Wunsch, C., 2006: Discrete Inverse and State Estimation Problems: With Geophysical Fluid Applications. Cambridge University Press, 371 pp.

—, and P. Heimbach, 2007: Practical global oceanic state estimation. Physica D, 230, 197-208.

Zang, X., and C. Wunsch, 2001: Spectral description of lowfrequency oceanic variability. J. Phys. Oceanogr., 31, 30733095 . 